Supporting Information for:

\title{
Intracellular Nonenzymatic In Situ Growth of Three-Dimensional DNA Nanostructures for Imaging Specific Biomolecules in Living Cells
}

Ran Liu, ${ }^{[a]}$ Songbai Zhang, ${ }^{[a, b]}$ Ting-Ting Zheng, ${ }^{[a]}$ Yan-Ru Chen, ${ }^{[a]}$ Jing-Ting $W u,{ }^{[a]}$ and Zai-Sheng $W u^{[a] *}$

${ }^{a}$ Cancer Metastasis Alert and Prevention Center, Fujian Provincial Key Laboratory of Cancer Metastasis Chemoprevention and Chemotherapy, National \& Local Joint Biomedical Engineering Research Center on Photodynamic Technologies, Pharmaceutical Photocatalysis of State Key Laboratory of Photocatalysis on Energy and Environment, College of Chemistry, Fuzhou University, Fuzhou, 350002, China

${ }^{\mathrm{b} C o l l e g e ~ o f ~ C h e m i s t r y ~ a n d ~ M a t e r i a l s ~ E n g i n e e r i n g, ~ H u n a n ~ U n i v e r s i t y ~ o f ~ A r t s ~ a n d ~ S c i e n c e, ~ C h a n g d e, ~ 415000, ~}$ China 


\title{
Table of Contents
}

\section{Section A: Experimental details}

\author{
A1. Materials
}

A2. Experimental procedures for the figures in the text

A2.1. Electrophoresis mobility shift assay (Figure 1b)

A2.2. Fluorescent spectroscopic measurements (Figure 1d, Figure 1e)

A2.3. Atomic force microscopic imaging (Figure 1c)

A2.4. miRNA imaging inside live cells (Figure 2b, Figure 2d)

A2.5. Flow Cytometric Assay (Figure 2c, Figure 2e)

A2.6. Real-time fluorescence analysis of miRNA in living cells (Figure 3a, Figure 3b and Figure 3c)

A2.7. Z-stack analysis of MCF-7 live-cells (Figure 3d)

\section{Section B: Supporting tables}

Table S1. Sequences of DNA oligonucleotides used in this work

Table S2. Hairpin probes used in the nPAGE experiments

\section{Section C: Supporting Figures}

\section{Section D: References}




\section{A1. Materials}

All oligonucleotides used in this study were synthesized by Shanghai Sangon Biological Engineering Co., Ltd. (Shanghai, China) and purified by HPLC. Their sequences are shown in Table S1. For stock solution preparation, all DNA sequences were dissolved and diluted with PBS buffer to the final concentration of $10 \mu \mathrm{M}$. After annealing at $90{ }^{\circ} \mathrm{C}$ for $5 \mathrm{~min}$, the resulting solutions were cooled down to room temperature and stored at $4{ }^{\circ} \mathrm{C}$ until use.

Dulbecco's Modified Eagle Medium (DMEM; HyClone, China), RPMI-1640 medium (HyClone, China), penicillin-streptomycin (Genview, USA), Fetal Bovine Serum (Genview, USA), MTT stock solution (Sigma, USA), phosphate buffered saline (PBS buffer) $\left(137 \mathrm{mM} \mathrm{NaCl}, 2.7 \mathrm{mM} \mathrm{KCl}, 10 \mathrm{mM} \mathrm{Na}_{2} \mathrm{HPO}_{4}, 2 \mathrm{mM} \mathrm{KH}{ }_{2} \mathrm{PO}_{4}, \mathrm{pH}=7.4\right.$; HyClone, China), $\beta$-estradiol ( $\mathrm{E}_{2}$ ) and Trizol Reagent Kit (Invitrogen, USA) were purchased from Beijing DingGuo Biotechnology Co. (Beijing, China). Lipofectamine 3000 (Lip3000) transfection reagent was purchased from Invitrogen (USA). Opti-MEM Medium and phenol red-free RPMI-1640 medium were provided by Gibco through Life Technology (Beijing, China). Other reagents (analytical grade) were purchased from Sinopharm Chemical Reagent Co. (Shanghai, China). The double-distilled water was purified by Kerton lab MINI water purification system (UK) with an electrical resistivity of $18.25 \mathrm{M} \Omega$.

\section{A2. Experimental procedures for the figures in the text}

A2.1. Electrophoresis mobility shift assay (Figure 1b). The experiment details are seen in the section of "METHODS"

A2.2. Fluorescent spectroscopic measurements (Figure 1d, Figure 1e). The experimental procedure is similar to that adopted in A2.4. Specifically, all the DNA sequences were sequentially added to PBS buffer, and the solution volume was adjusted to $25 \mu \mathrm{L}$. After incubation at $37^{\circ} \mathrm{C}$ for $120 \mathrm{~min}$, the resulting solution was diluted to $200 \mu \mathrm{L}$ with PBS buffer and is ready for fluorescence measurement. Their final concentrations are as follows: $100 \mathrm{nM} \mathrm{HA}, 100 \mathrm{nM} \mathrm{HB}, 100 \mathrm{nM}$ HC-Cy5, $100 \mathrm{nM}$ TH and $25 \mathrm{nM}$ miR-21D or nontarget species (at a molar ratio of 4:4:4:4:1). The symbols "+" and "-", indicate the presence and absence of the corresponding strands, respectively.

A2.3. Atomic force microscopic imaging (Figure 1c). The experiment details are seen in the section of "METHODS".

\section{A2.4. miRNA imaging inside live cells (Figure 2b, Figure 2d).}

Cell imaging of Figure 2b: MCF-7 cells were seeded on 22-mm coverslips and cultured in 12-well palstic-botton plates. When grown to a confluency of $70 \sim 80 \%$, the cells were washed thrice with PBS buffer. Then, the cells were incubated at $37^{\circ} \mathrm{C}$ for 220 min in $400 \mu \mathrm{L}$ of transfection solution that was prepared by adding HA, HB, HC-Cy5 and/or TH-FAM (each $2 \mu \mathrm{L}, 10 \mu \mathrm{M}$ ) and Lip3000 into Opti-MEM medium according to the instruction. The final concentration of the four probes was $50 \mathrm{nM}$. After staining the cell nuclei with Hoechst, the cell imaging was performed on a Leica SP8 laser scanning confocal microscope (Leica, Germany). More experimental details are seen in the section of "METHODS".

The detailed information on the cell lines and corresponding probes is described as followed:

Group I: MCF-7 cells; HA, HB, HC-Cy5 and TH-FAM;

Group II: MCF-7 cells treated with $\mathrm{E}_{2}$; HA, HB, HC-Cy5 and TH-FAM;

Group III: MCF-7 cells; HA, HB, HC-Cy5, TH-FAM and anti-miR-21D;

Group IV: MCF-7 cells; HA, HB and HC-Cy5;

Group V: L-02 cells; HA, HB, HC-Cy5 and TH-FAM;

For Group II, MCF-7 cells were pre-treated with $\mathrm{E}_{2}$. Specially, MCF-7 cells were incubated for $24 \mathrm{~h}$ at $37{ }^{\circ} \mathrm{C}$ in $400 \mu \mathrm{L}$ of $\mathrm{E}_{2}$-contained solution that was prepared via dissolving $\mathrm{E}_{2}$ in ethyl alcohol and then diluting to $10 \mathrm{nM}$ with complete DMEM medium. 
Comparing NEPA imaging with FISH method (Figure 2d): The assay experiments were performed according to the same procedure as Figure 2b, but only TH-Cy5 was used for FISH-based imaging.

\section{A2.5. Flow Cytometric Assay (Figure 2c, Figure 2e)}

Cells were cultured in the corresponding medium on 6-well plastic-bottom plates for $24 \mathrm{~h}$ at $37{ }^{\circ} \mathrm{C}$ in a humidified incubator with $5 \% \mathrm{CO}_{2}$. When grown to $70 \sim 80 \%$ confluency, the cells were washed with PBS buffer and transfected with the mixture of DNA probes with the help of Lip3000 according to the instruction as described in Section A2.4. The volume of transfection solution was $1000 \mu \mathrm{L}$, while the final concentration of HA, HB, HC-Cy5 and TH-FAM was $50 \mathrm{nM}$. Subsequently, the cells were washed with PBS buffer, digested with $0.25 \%$ trypsin $(1000 \mu \mathrm{L})$ at $37{ }^{\circ} \mathrm{C}$ for $10 \mathrm{~min}$ and centrifuged. After suspending in $1000 \mu \mathrm{L}$ of PBS buffer, the cells are ready for flow cytometric analysis that was performed on a BD FACSAria flow cytometry (BD Biosciences, USA). A $633 \mathrm{~nm}$ laser was used as the exciting source to measure the fluorescence intensity of Cy5. Each measurement used 10,000 cells. The cells without being transfected with DNA probes were used as the control.

\section{A2.6. Real-time fluorescence analysis of miRNA in living cells (Figure 3a, Figure $3 \mathrm{~b}$ and Figure 3c).}

HeLa cells were cultured in the complete DMEM medium for $24 \mathrm{~h}$ on a 20 -mm glass-bottom culture dish (NEST Biotechnology, China). When grown to $70 \sim 80 \%$ confluency and washed thrice with PBS buffer, the cells were incubated at $37^{\circ} \mathrm{C}$ in $400 \mu \mathrm{L}$ of transfection solution that was prepared by adding four DNA probes (HA, HB, HC-Cy5 and TH-FAM, each $2 \mu \mathrm{L}, 10 \mu \mathrm{M}$ ) and Lip3000 into Opti-MEM medium and adjusting the final volume according to the instruction. The final concentration of each probe was $50 \mathrm{nM}$. During the whole transfection process, the glass bottom culture-dish was placed in a humid atmosphere with $5 \% \mathrm{CO}_{2}$ at $37^{\circ} \mathrm{C}$. Cell images at different time points were acquired on a Leica SP8 laser scanning confocal microscope (Leica, Germany).

Figure $3 \mathrm{~b}$ shows the fluorescence images of given local areas within a representative HeLa cell described in Figure 3a. Moreover, the fluorescence intensity of images, including the whole area and different local areas, is shown in Figure 3c.

\section{A2.7. Z-stack analysis of MCF-7 live-cells (Figure 3d)}

MCF-7 cells were cultured in the complete DMEM medium for $24 \mathrm{~h}$ on a 20-mm glass bottom culture-dish. When grown to $70 \sim 80 \%$ confluency and washed with PBS buffer, the cells were transfected with DNA probes (HA, HB, HC-Cy5 and TH-FAM) with the help of Lip3000 according to the same procedure described in Section A2.4. After washing with PBS buffer and adding complete DMEM medium $(400 \mu \mathrm{L})$, the glass-bottom culture-dish was placed was placed at $37^{\circ} \mathrm{C}$ in a humid atmosphere with $5 \%$ $\mathrm{CO}_{2}$. The 3D Z-stack projections were carried out on a Leica SP8 laser scanning confocal microscope (Leica, Germany). Cellular images at Green channel (FAM) and Red channel (Cy5) and Merge (FAM and Cy5 with DIC) in the Z-stack were acquired at 1.5- $\mu \mathrm{m}$ Z-axis intervals. Scale bar: $10 \mu \mathrm{m}$. To directly visualize the relative location of opened TH-FAM and HC-Cy5, their fluorescence intensities at every Z-axis plane were extracted by Image J software. Moreover, the Manders overlap coefficients (MOC) were represented to quantitatively evaluate the degree of colocalization between the fluorescence signals of TH-FAM and DNA NSs. 


\section{Section B: Supporting Tables}

Table S1. Sequences of DNA oligonucleotides used in this work. ${ }^{\mathrm{a}}$

\begin{tabular}{|c|c|}
\hline Name & Sequence $\left(5^{\prime}-3^{\prime}\right)$ \\
\hline \multicolumn{2}{|l|}{ Precursors of NS } \\
\hline Hairpin A (HA) & ATGTGATACTTGGGTCGTTCCTTGCAAGATCAAACCCAAGGAACGacccaagcttgggt \\
\hline Hairpin B (HB) & ATGCGTTCCTTGGGTTTGATCTTGCAAGTATCAACCCAAGATCAAacccaagcttgggt \\
\hline Hairpin C (HC) & ATGTTGATCTTGGGTTGATACTTGCAAGGAACGACCCAAGTATCAacccaagcttgggt \\
\hline Cy5-modified HC (HC-Cy5) & ATGTTGAT/Cy5/CTTGGGTTGATACTTGCAAGGAACGACCCAAGTATCAacccaagct/BHQ-2/tgggt \\
\hline \multicolumn{2}{|l|}{ The sequence of Triggers } \\
\hline Trigger Probe (TP) & CAAGGAACGACCCAAGTATCACAT \\
\hline Trigger Hairpin (TH) & ACGACCCAAGTATCACATTCAACATCAGTCTGATAAGCTATTTTTTCTGATGTTGAATGTGATA \\
\hline Trigger Hairpin with a long sticky end (L-TH) & CAAGGAACGACCCAAGTATCACATTCAACATCAGTCTGATAAGCTATTTTTTCTGATGTTGAATGTGATA \\
\hline Trigger Hairpin with a short sticky end (S-TH) & CCCAAGTATCACATTCAACATCAGTCTGATAAGCTATTTTTTCTGATGTTGAATGTGATA \\
\hline FAM-modified TH (TH-FAM) & ACGACCCAAGT/FAM/ATCACATTCAACATCAGTCTGATAAGCTATTTTTTCTGATGTTGAATGTGATA/BHQ-2/ \\
\hline Cy5-modified TH (TH-Cy5) & ACGACCCAAGT/Cy5/ATCACATTCAACATCAGTCTGATAAGCTATTTTTTCTGATGTTGAATGTGATA/BHQ-2/ \\
\hline \multicolumn{2}{|l|}{ Non- palindrome precursors of NS } \\
\hline non-palindrome $\mathrm{HA}$ (nHA) & ATGTGATACTTGGGTCGTTCCTTGCAAGATCAAACCCAAGGAACGACCCAAG \\
\hline non-palindrome $\mathrm{HB}$ (nHB) & ATGCGTTCCTTGGGTTTGATCTTGCAAGTATCAACCCAAGATCAAACCCAAG \\
\hline non-palindrome $\mathrm{HC}(\mathrm{nHC})$ & ATGTTGATCTTGGGTTGATACTTGCAAGGAACGACCCAAGTATCAACCCAAG \\
\hline \multicolumn{2}{|l|}{ Target or nontarget miRs (DNA analogues) } \\
\hline miR-21D & TAGCTTATCAGACTGATGTTGA \\
\hline $\mathrm{miR}-141 \mathrm{D}$ & TAACACTGTCTGGTAAAGATGG \\
\hline $\operatorname{miR}-222 \mathrm{D}$ & CTCAGTAGCCAGTGTAGATCCT \\
\hline R-let-7fD & TGAGGTAGTAGTAGATTGTATAGTT \\
\hline miR-141 & UAACACUGUCUGGUAAAGAUGG \\
\hline miR-200b & UAAUACUGCCUGGUAAUGAUGA \\
\hline $\operatorname{miR}-429$ & UAAUACUGUCUGGUAAAACCGU \\
\hline Let-7d & AGAGGUAGUAGGUUGCAUAGUU \\
\hline \multicolumn{2}{|l|}{ Antisense DNA of miR-21 } \\
\hline anti-miR-21D & TCAACATCAGTCTGATAAGCTA \\
\hline \multicolumn{2}{|l|}{ Primers for qPCR of miR-21 and GAPDH } \\
\hline forward primer (miR-21) & GCCGCTAGCTTATCAGACTGATGT \\
\hline reverse primer (miR-21) & GTGCAGGGTCCGAGGT \\
\hline forward primer (GAPDH) & CATGGCCTTCCGTGTTCCTA \\
\hline reverse primer (GAPDH) & CCTGCTTCACCACCTTCTTGAT \\
\hline \multicolumn{2}{|l|}{ The sequence of trigger AS1411 } \\
\hline Trigger AS1411 (TA) & CAAGGAACGACCCAAGTATCACATTTTTTTTTGGTGGTGGTGGTTGTGGTGGTGGTGG \\
\hline TA-Cy5 & CAAGGAACGACCCAAGTATCACATTTT/Cy5/TTTTTGGTGGTGGTGGTTGTGGTGGTGGTGG \\
\hline Random DNA-Cy5 & ACTCGTTCTAAAGCGCGCGCGCTATCAGGTAAGCAGGTTAGTAGTGCCCCCGGGGGCTT/Cy5/TTGTGTGATATG \\
\hline
\end{tabular}

aThe underlined fragments indicate the self-complementary portions of hairpin probes. The bold portion in Trigger hairpin (TH) indicates the binding site of miR-21 target molecule. Trigger AS1411 (TA) is designed via prolonging the original sequence of aptamer AS1411 (boxed, capable of specifically binding to nucleolin) by adding a triggering fragment in italic the 5 '-end. The fragments in lowercase are the palindromic sequences, and the regions in italic are partly complementary to HA. 
Table S2. Hairpin probes used in the nPAGE experiments.

\begin{tabular}{|c|c|c|c|c|c|c|}
\hline Hairpins of NEPA in Figures & HA & HB & $\mathrm{HC}$ & nHA & nHB & nHC \\
\hline Figure S2a & $\checkmark$ & $\checkmark$ & $\checkmark$ & & & \\
\hline Figure S2b & & & & $\checkmark$ & $\checkmark$ & $\checkmark$ \\
\hline Figure S2c & & & $\checkmark$ & $\checkmark$ & $\checkmark$ & \\
\hline Figure S4 & & $\checkmark$ & $\checkmark$ & $\checkmark$ & & \\
\hline Figure S5 & $\checkmark$ & & $\checkmark$ & & $\checkmark$ & \\
\hline Figure S6 & $\checkmark$ & $\checkmark$ & & & & $\checkmark$ \\
\hline
\end{tabular}


Section C: Supporting figures

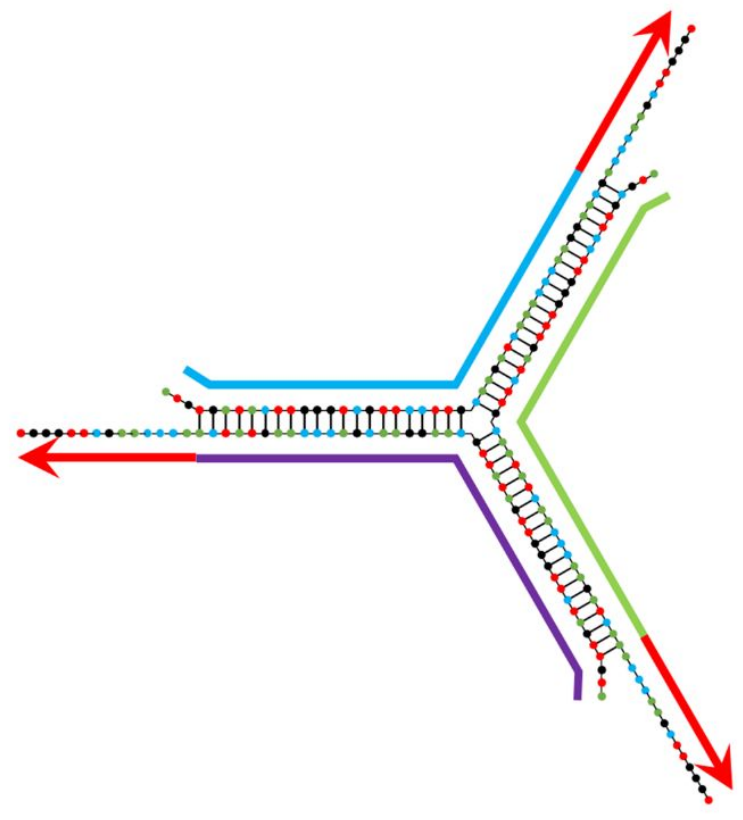

$\begin{array}{llll}- & \ddots & \bullet & \bullet \\ \text { A } & \text { T } & \text { G } & \text { C }\end{array}$

Figure S1. The basic structural unit of DNA nanosphere (NS) products. 


\section{Molecular mechanism for NEPA assembly for the preparation of NS}

As shown in Figure S2a, the native polyacrylamide gel electrophoresis (nPAGE) analysis directly confirms the feasibility of NEPA-based assembly of DNA NS. It is reasonable that no obvious difference in the band is observed between Lanes 1, 2 and 3 because HA, HB and HC have the same number of bases and similar secondary structure (loop-stem structure). For Lane 4 where three hairpin components co-exists, only one band without no electrophoretic mobility shift is detected, demonstrating that the intermolecular interaction cannot occur even though the three hairpin probes are partly complementary to each other. In contrast, upon the addition of TP, the hairpin band disappears and a new band with dramatically retarded electrophoretic mobility is observed in Lane 7. These results demonstrate that TP is capable of efficiently triggering the NEPA-based assembly, forming the DNA nanospheres with very high molecular weight (MW). Moreover, if taking into account the concentration relationship between hairpin probes (each one concentration, $800 \mathrm{nM}$; total concentration, $2400 \mathrm{nM})$ and TP $(200 \mathrm{nM})$, it is clear that one TP can induce the self-assembly of many hairpin probes, achieving the strand-displacement amplification effect. A possible molecular mechanism for the NEPA assembly of DNA NS is schematically described in the right part to highlight the essential function of palindromic sticky ends. More details are described in Scheme 1, where the NEPA assembly process is divided into four stages: Stage I, Stage II, Stage III and Stage IV. The difference in DNA band between Lane 1 and Lane 5 demonstrate the hybridization of TP with HA (Stage I). Similarly, the gradual change of DNA band in Lane 6 and Lane 7 indicates that TP/HA duplex can successively hybridize with HB (Stage II) and HC (Stage III, accompanied by subsequent Stage IV, the cross-linking between a large number of Y-DNAs by the hybridization of palindromic sticky ends).

In order to offer more information on the NEPA assembly, two control experiments were carried out by controlling the type of hairpin probes. As shown in Lane 5, besides the residual hairpin band, we observe two new bands with high MW that should be attributed to the formation of DNA duplex from the hybridization of HA with TP and corresponding duplex dimer (D-dimer) composed of two HA probes and two TP triggers by the base pairing of active palindromic fragments. After introduction of another probe HB (Lane 6), compared with Lane 5, HA-TP duplex band and D-dimer disappear, and another two new bands with lower mobility (although very weak) are observed. This is because all the HA-TP duplexes and D-dimers were exhausted due to the hybridization with a sufficient amount of HB probes $(800 \mathrm{nM})$, resulting in the formation of HA-TP-HB triplex and DNA pentaplex. Nevertheless, no obvious change is detected in the hairpin band compared with Lane 5, implying that hybridized TP cannot be displaced and circularly induce the assembly of hairpin probes even if HA and HB co-exist in the solution. Additionally, owing to the branched structure, ${ }^{1-2}$ HA-TP-HB triplex exhibits the slower gel mobility than D-dimer even if it has a lower MW.

To futher examine the function of palindromic sequences, we employed nHA, nHB and nHC instead of HA, HB and $\mathrm{HC}$, respectively. The assembly was performed under identical conditions, and the nPAGE analyses were conducted to evaluate NEPA assembly efficiency. As shown in Figure S2b, there is only one new nHA-TP duplex in Lane 5, while D-dimer products cannot be obtained due to the lack of palindromic fragment in HA. Correspondingly, in Lane 6, there is only one band of nHA-TP-nHB triplex in the range of high MW that was formed from the hybridization of nHA-TP duplex with nHB. Moreover, upon addition of $\mathrm{nHC}$, this triplex band does not exhibit the obvious change as shown in Lane 7 where only a very weak Y-DNA band appears. Besides, the $\mathrm{nHC}$ band is still very clear. Presumably, without the aid of palindromic fragment, the nHC could not efficiently replace the TP from Triplex and thus Y-shaped DNA is unable. Moreover, the DNA complex assembled from hybridization of nHA-TP-nHB trimer with nHC is not table enough since there is no the corresponding gel band and a considerable amount of nHC probes are still not consumed. These results indicate that the palindromic fragment of $\mathrm{HC}$ probe plays an important role in the displacement reaction of hybridized TP, which is further verified by the gel images in Figure S2c where nHA and nHB were used instead of HA and HB, respectively. Namely, the terminal palindromic fragments of HA and HB were removed, while the palindromic fragment of $\mathrm{HC}$ was still retained. The removal of palindromic fragment from hairpin probes is verified by the difference in electrophoretic band 
between Lane 3 and Lane 1 (or Lane 2). Along this line, Lane 7 exhibits two impressive bands with small mobility shifts substantially different from the bands in Lane 6, demonstrating the formation of Y-DNA and Y-dimer made of two Y-DNA units. Moreover, the bands of nHA, nHB and HC almost completely disappear even if the TP concentration (200 nM) is much lower than hairpin probes (each $800 \mathrm{nM}$ ). That is to say, TP in nHA-TP-nHB triplex is efficiently displaced by HC under the synergistic effect of palindromic fragments and thereby triggers the assembly of hairpins in a cyclical procedure. Moreover, the palindromic fragments in Y-DNA units can interact with each other to some extent. Nevertheless, the expected DNA NS superstructure cannot be successfully assembled from nHA, nHB and $\mathrm{HC}$, which is confirmed by the substantial difference in the gel band between Lane 7 and Lane 8 because each Y-dimer assembled from nHA-nHB-HC has only one palindromic sticky end and thus is unable to exert the hierarchical assembly.

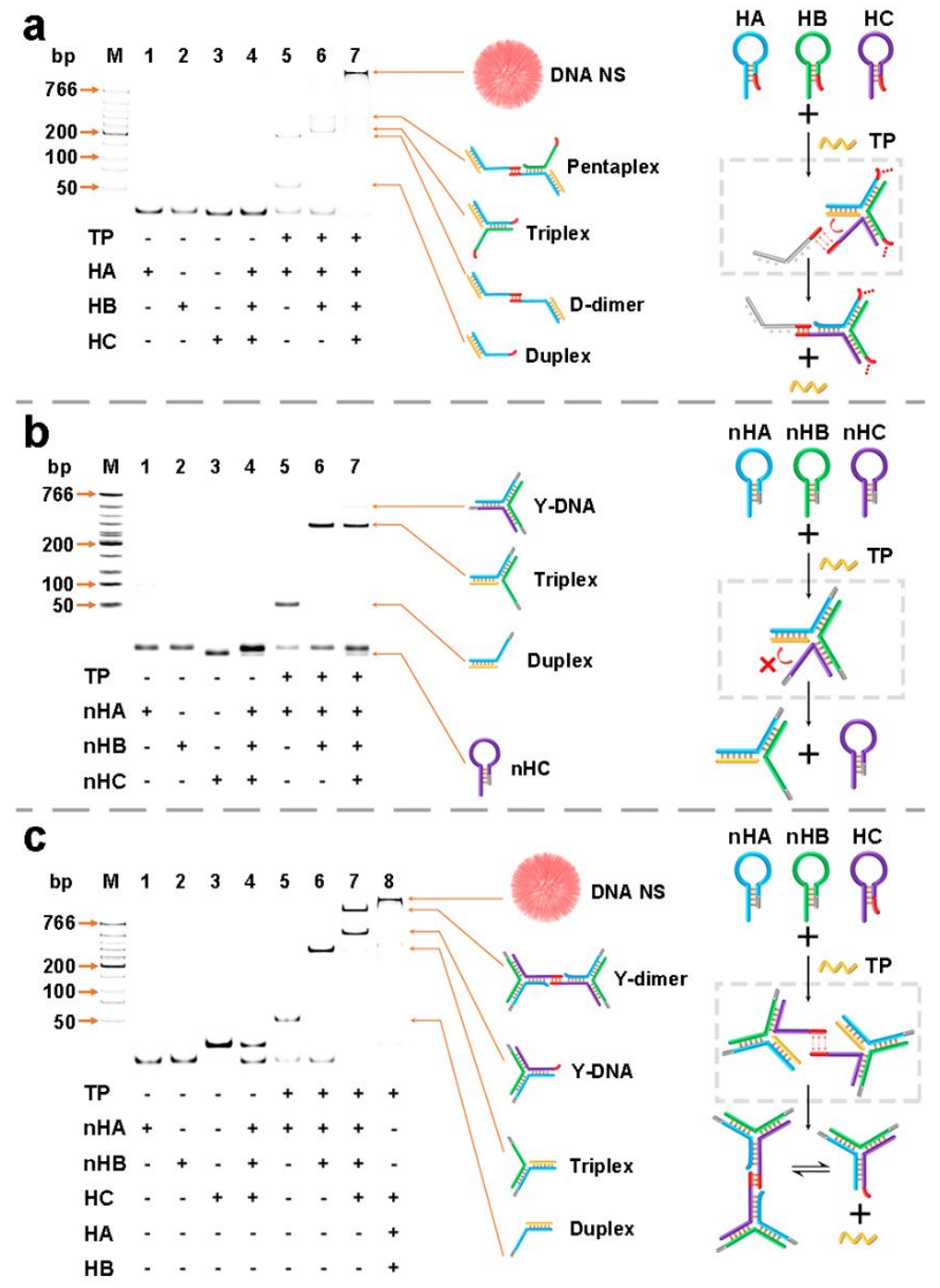

Figure S2. The nPAGE characterization of (a) stepwise assembly of NEPA products, DNA NS, consisting of HA, HB and HC, (b) products assembled from non-palindromic hairpin probes (nHA, nHB and nHC) and (c) products assembled from the mixture of nHA and nHB with HC. The DNA NS products are shown in Lane 8 to present the direct comparison. The concentration of each hairpin probe is $800 \mathrm{nM}$, while $200 \mathrm{nM}$ TP was used. To illustrate the essential function of palindromic sticky ends in a comparative 
fashion, the possible molecular mechanism for the formation of DNA assembled products in Lane 7 is schematically described in the right part of panels (a), (b) and (c).

\section{Experimental procedure:}

All DNA solutions were mixed and diluted with PBS buffer to $25 \mu \mathrm{L}$. The final concentrations of DNA probes are as follows: 800 nM HA (or nHA), $800 \mathrm{nM} \mathrm{HB}$ (or nHB), $800 \mathrm{nM} \mathrm{HC}$ (or nHC) and $200 \mathrm{nM} \mathrm{TP}$. After incubation at $37^{\circ} \mathrm{C}$ for $120 \mathrm{~min}$, nPAGE was run in $0.5 \times$ TBE buffer at $80 \mathrm{~V}$ for $90 \mathrm{~min}$. Low MW DNA ladder (New England Biolabs, China) was used as the marker. For the preparation of control solutions, an equal volume of PBS buffer was used instead of the corresponding DNA probes. More details are described in the section of "METHODS". 


\section{NEPA-based sequential assembly process}

To further confirms that DNA NS is assembled in the desinged sequence (from Stage I, to Stage II, and then to Stage III, and finally to Stage IV) ranther than in another manner (for example, from Stage I, to Stage III, then to Stage II, and finally to Stage IV), the assembly was performed in the absence of HB and characterized by nPAGE analysis. As shown in Figure S3, there is no obvious difference between Lane 4 and Lane 5, demonstratining that HA-TP duplex cannot open the HC. It is reasonable because the week base-paring interaction (21 base pairs) between HA and HC disables the displacement of TP in HA-TP duplex (24 base pairs) and HC opening. Namely, TP initiates the NEPA assembly process only in the sequence: HA, HB and then HC.

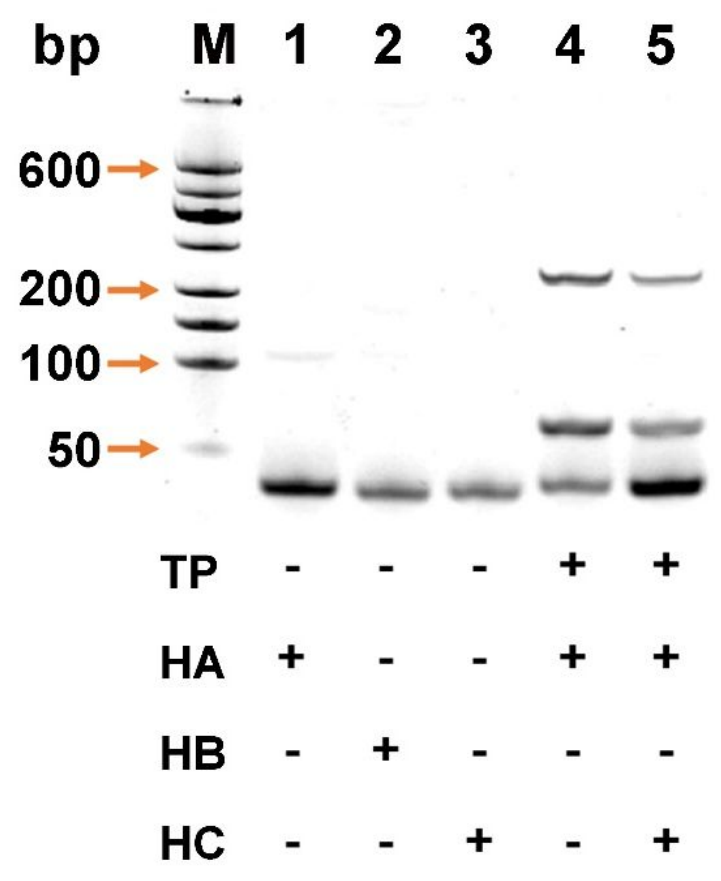

Figure S3. The nPAGE analysis for further confirming the NEPA assembly sequence of NS products. The concentration of each hairpin probe was $800 \mathrm{nM}$, while $200 \mathrm{nM}$ TP was used.

\section{Experimental procedure:}

All DNA solutions were mixed and diluted with PBS buffer to $25 \mu \mathrm{L}$. The final concentrations of DNA probes are as follows: 800 nM HA, $800 \mathrm{nM} \mathrm{HB}, 800 \mathrm{nM} \mathrm{HC}$ and $200 \mathrm{nM}$ TP. After incubation at $37^{\circ} \mathrm{C}$ for $120 \mathrm{~min}$, nPAGE was run in $0.5 \times \mathrm{TBE}$ buffer at 80 $\mathrm{V}$ for $90 \mathrm{~min}$. Low MW DNA ladder (New England Biolabs, China) was used as the marker. When needed, an equal volume of PBS buffer was used instead of the corresponding DNA probes. More details are described in the section of "METHODS". 


\section{The dependence of NEPA assembly on the palindromic fragment in each of hairpin components}

As shown in Figure S4 and Figure S5, compared with panel (b) and panel (a) in Figure S2a, Lane 6 and Lane 7 show more gel bands, indicating the formation of various assembled products with higher MW. This is reasonable because the intermediates, Triplex with one palindromic sticky end and Y-DNA with two palindromic sticky ends, can further self-assemble into different products with more complex structures. Nevertheless, since HA (or HB) were substituted by nHA (or nHB), Y-DNA unit has only two (rather than three) sticky ends and more stable DNA NS products cannot be achieved. Additionally, similar to Figure S2b, when $\mathrm{nHC}$ was used instead of $\mathrm{HC}$ for the assembly of DNA products, the hybridized TP cannot be displaced even if the other two hairpin probes (HA and HB) each have palindromic fragment. The supporting data are shown in Figure S6. A bright nHC band is observed in lane 7 and no substantial difference in the bands is detected between Land 6 and Lane 7, demonstrating that most of nHC were not consumed.

Additionally, according to the experimental results mentioned above, the palindromic sticky end designed in HC can promote the displacement and recycle of TP (although to different extents) even if nHA and/or nHB are used (instead of HA and HB, respectively), but the incompletely assembled DNA products are susceptible to the nuclease-mediated degradation compared with the expected DNA NS superstructures. This is confirmed by the serum stability assay experiments as shown in Figure S4b and Figure S5b.

Overall, the following conclusions can be drawn: firstly, by designing the palindromic sequence at the end of three hairpin probes, we can efficiently construct DNA NS superstructure by NEPA-based assembly in response to specific external stimuli (not DNA building components themselves); secondly, the terminal palindrome segment in HC probe is indispensable for the displacement of TP to form the Y-DNA units; thirdly, all the active palindromic fragments in the opened HA, HB or HC probes play a significant role in the successful assembly of DNA NS superstructures.

\section{a}

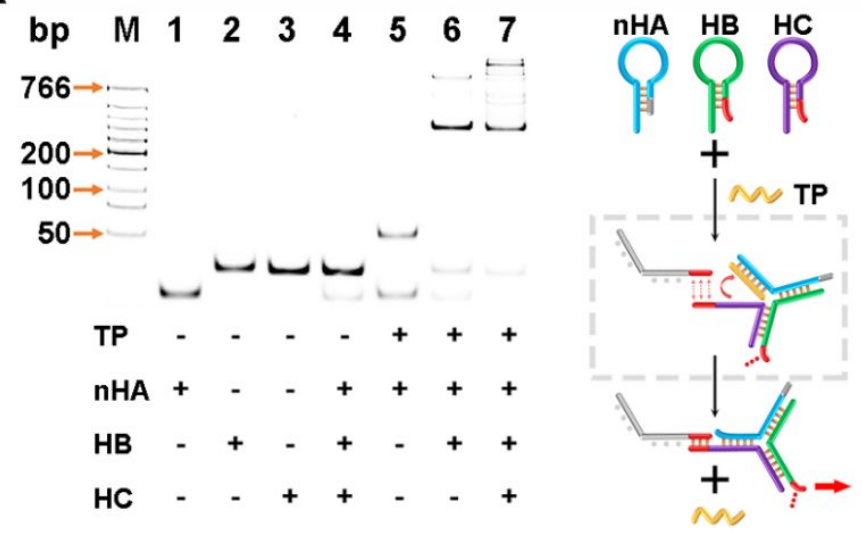

b

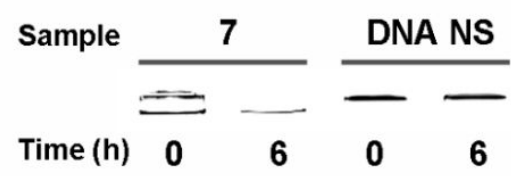

Figure S4. Effect of the palindromic fragment in Hairpin A on NEPA assembly efficiency. (a) nPAGE characterization of stepwise assembly of control system composed of nHA, HB and HC, where nHA has no the palindromic fragment at its 3' end. "+" and "--" indicate the presence and absence of the corresponding strands, respectively. The possible molecular mechanism for the formation 
of DNA assembled products in Lane 7 is schematically outlined in the right part. (b) Serum stability assay of assembled products in Lane 7 of panel (a) and DNA NS by nPAGE.

\section{Experimental procedure:}

Panel (a): All DNA solutions were mixed and diluted with PBS buffer to $25 \mu \mathrm{L}$. The final concentrations of DNA probes are as follows: $800 \mathrm{nM}$ nHA (or HA), $800 \mathrm{nM} \mathrm{HB}, 800 \mathrm{nM} \mathrm{HC}$ and $200 \mathrm{nM}$ TP. After incubation at $37{ }^{\circ} \mathrm{C}$ for $120 \mathrm{~min}$, nPAGE was run in $0.5 \times \mathrm{TBE}$ buffer at $80 \mathrm{~V}$ for $90 \mathrm{~min}$. Low MW DNA ladder (New England Biolabs, China) was used as the marker. For the preparation of control solutions, an equal volume of PBS buffer was used instead of the corresponding DNA probes.

Panel (b): The sample was prepared by adding $6 \mu \mathrm{L}$ of fetal bovine serum into $14 \mu \mathrm{L}$ of NEPA assembled products and mixing thoroughly. After incubation at $37^{\circ} \mathrm{C}$ for $6 \mathrm{~h}$, the mixture was immediately used for nPAGE analysis. The final serum concentration is $30 \%(\mathrm{v} / \mathrm{v})$. More details are described in the section of "METHODS".

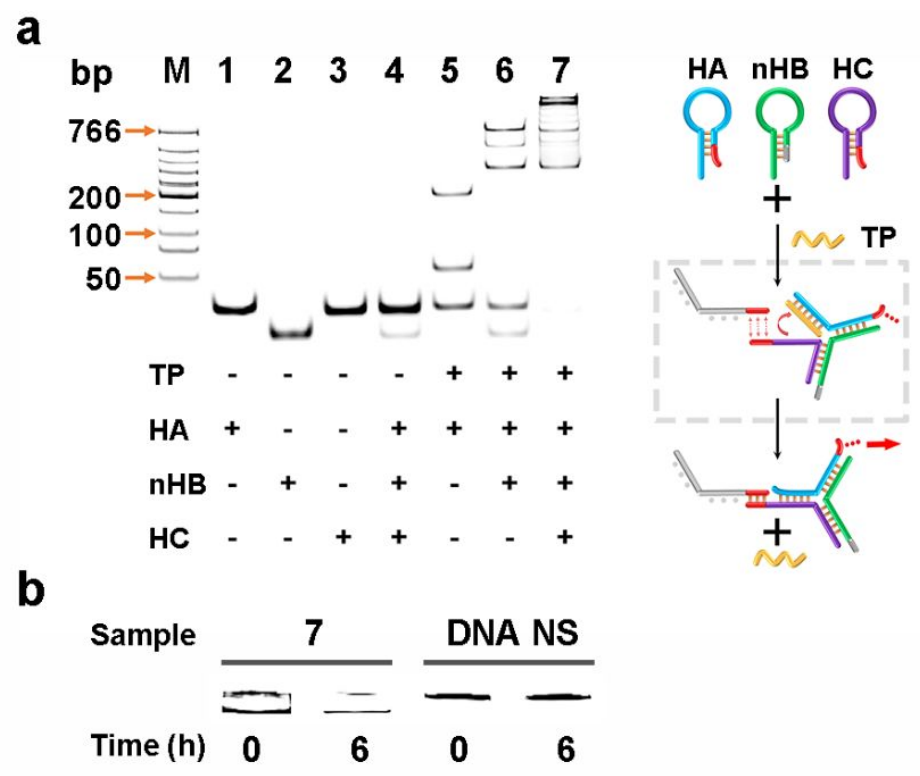

Figure S5. Effect of the palindromic fragment in Hairpin B on NEPA assembly efficiency. (a) nPAGE characterization of stepwise assembly of control system composed of HA, nHB and HC, where nHB was designed to have no palindromic fragment at the 3 ' end. "+" and "." indicate the presence and absence of the corresponding strands, respectively. The possible molecular mechanism for the formation of DNA assembled products in Lane 7 is schematically outlined in the right part. (b) Serum stability assay of self-assembled products in Lane 7 of panel (a) and DNA NS by nPAGE.

\section{Experimental procedure:}

Panel (a): The assembly of DNA nanoobjects and their serum stability assay were performed according to the procedure described in Figure S4.

Panel (b): The sample was prepared by adding $6 \mu \mathrm{L}$ of fetal bovine serum into $14 \mu \mathrm{L}$ of NEPA assembled products and mixing thoroughly. After incubation at $37^{\circ} \mathrm{C}$ for $6 \mathrm{~h}$, the mixture was immediately used for nPAGE analysis. The final serum concentration is $30 \%(\mathrm{v} / \mathrm{v})$. More details are described in the section of "METHODS". 

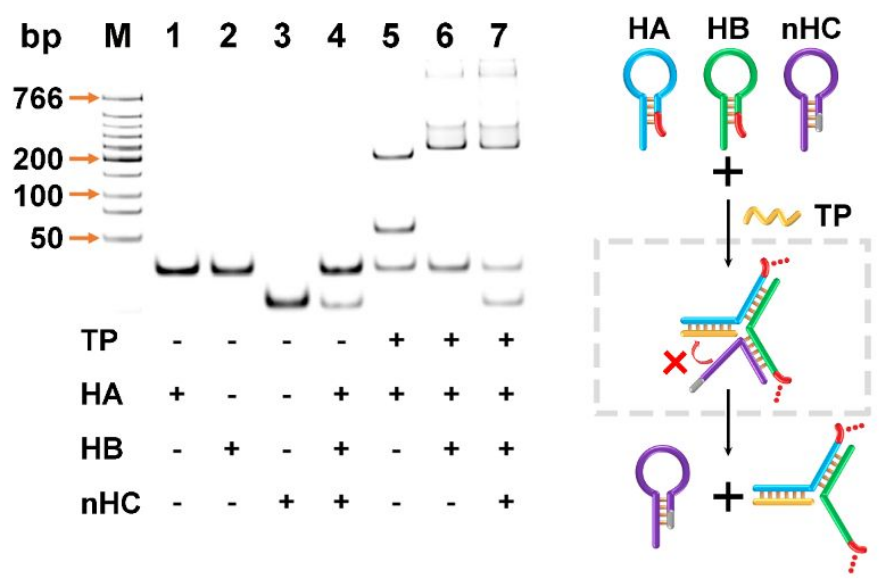

Figure S6. Effect of the palindromic fragment in Hairpin C on NEPA assembly efficiency. The stepwise assembly of control system composed of HA, HB and nHC was characterized by nPAGE, where nHC was designed to have no palindromic fragment at the 3' end. The symbols, "+” and “-”, indicate the presence and absence of the corresponding strands, respectively. The possible molecular mechanism for the formation of DNA assembled products in Lane 7 is schematically outlined in the right part. The hybridization experiments and electrophoretic characterization were carried out as described in Figure S4. 


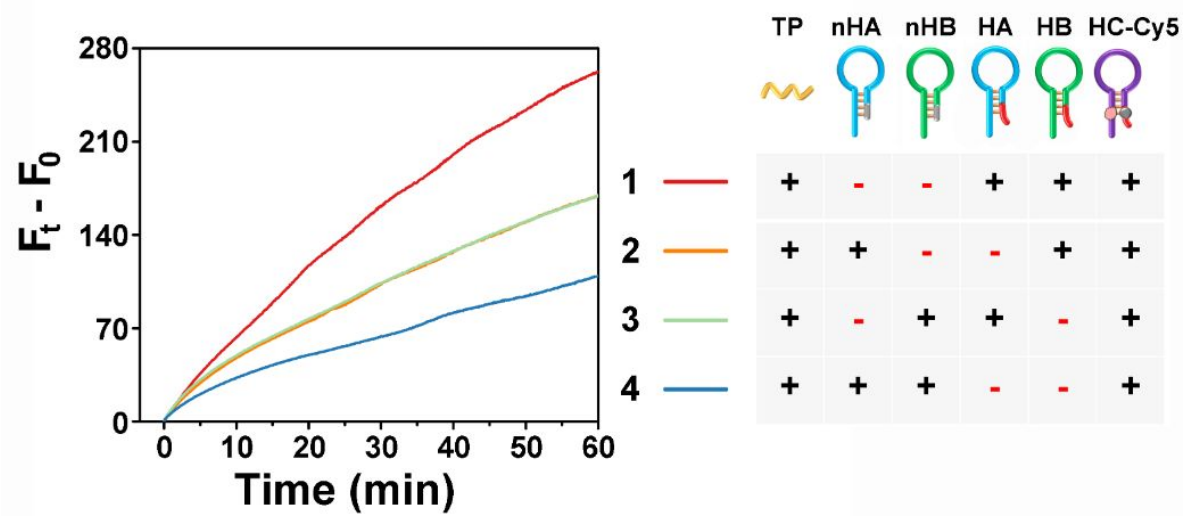

Figure S7. Real-time fluorescence monitoring of NEPA-based system and its control systems upon Trigger probe (TP). All the fluorescence measurements for different systems were performed under identical conditions, including the probe concentration and the order of probe addition. The relationship between the systems for fluorescence measurements and for gel electrophoretic analyses is described as follows: System 1, the same as the one explored in Figure S2a; System 2, the same as that in Figure S4a; System 3, the same as the one in Figure S5a; System 4, the same as the one in Figure S2c. However, HC-Cy5, a probe chemically modified with Cy5 and BHQ-2, was used instead of label-free HC in this section.

\section{Experimental procedure:}

The DNA probes were added to $150 \mu \mathrm{L}$ of PBS buffer, and then the solution volume was adjusted to $192 \mu \mathrm{L}$ with PBS buffer. After adding $8 \mu \mathrm{L}$ of $1 \mu \mathrm{M}$ TP, the fluorescence change was immediately monitored on a Hitachi F-7000 (Hitachi Ltd., Japan) with a Xenon lamp as the excitation source. The excitation wavelength was set as $632 \mathrm{~nm}$, and the emission wavelength at $660 \mathrm{~nm}$ was recorded. The final concentrations of DNA probes and target species were as follows: $100 \mathrm{nM} \mathrm{HA}$ (or nHA), $100 \mathrm{nM} \mathrm{HB}$ (or nHB), $100 \mathrm{nM}$ HC-Cy5 and $40 \mathrm{nM}$ TP. 


\section{Effect of TH sequence on NEPA assembly efficiency.}

In the initial stage, we designed the working TH and optimized its sequence. For in vitro experiments, the DNA mimics were used instead of the corresponding miRNAs of interest. As shown in Figure S8, three trigger hairpins, including L-TH, TH and S-TH, exhibit different the signal-to-noise ratios in the presence of target miR-21D. For the three hairpin probes, the black fragment has the same sequence, while the yellow fragment (triggering fragment) is designed to have different binding affinities for HA. Domain 1 contains a constant sequence to promote the formation of the loop-stem structure but the base number in Domain 2 is changed by extending the sticky end to regulate the hybridization stability between TH and HA (Figure S8a). Figure S8b demonstrates that, if Domain 2 is too long (e.g., 16 bases in L-TH), the strong fluorescence is detected regardless of whether or not target miR-21D is present. This is because Domain 2 with a long complementary fragment can directly open the hairpin structure of HA and initiate the NEPA assembly without the aid of target species. On the contrary, if Domain 2 is too short (e.g., 6 bases in S-TH), the fluorescence signal is very low even if in the presence of target miR-21D. It is reasonable that, although the target species hybridizes with the TP, the triggering fragment with a short Domain 2 is unable to open the HA hairpin and fail to initiate the subsequent assembly reaction. Only the TH with a 10-base-contained Domain 2 is suitable for the detection of target miR-21D since it exhibits a high signal-to-noise ratio resulting from the high target-induced fluorescence intensity and a low fluorescence background. The gel electrophoretic analyses represented in Figure S9 directly provide the convincing evidence for the feasibility of TH.
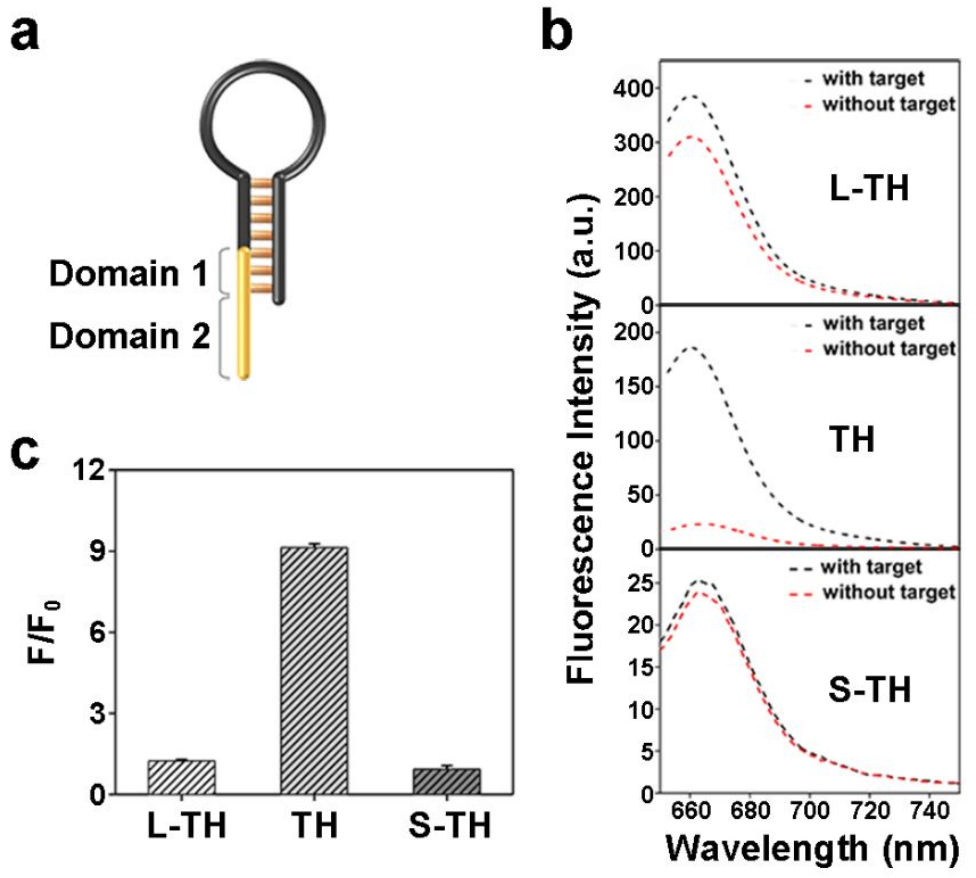

Figure S8. Effect of TH sequence on NEPA assembly efficiency. (a) Structural diagram of TH. Portion 1 promotes the formation of self-hybridization-based stem, while Portion 2 is a sticky end with different lengths for three TH probes ( 6 bases for S-TH, 10 bases for TH, and 16 bases for L-TH). (b) TH sequence-dependent fluorescence signal of NEPA-based system upon miR-21D. (c) The fluorescence ratio estimated from $\mathrm{F} / \mathrm{F}_{0}$, where $\mathrm{F}$ and $\mathrm{F}_{0}$ indicate the fluorescence intensity in the presence and absence of target miR-21D, respectively. The fluorescence intensities were recorded from the fluorescence spectra of (b). 


\section{Experimental procedure:}

All DNA probes were mixed and the solution volume was adjusted to $25 \mu \mathrm{L}$ with PBS buffer. After incubation at $37{ }^{\circ} \mathrm{C}$ for 120 min, the resulting solution was diluted to $200 \mu \mathrm{L}$ with PBS buffer, followed by fluorescent measurements on a Hitachi F-7000 (Hitachi Ltd. Japan) with a Xenon lamp as the excitation source. The final concentrations of hairpin probes were as follows: $100 \mathrm{nM}$ HA, $100 \mathrm{nM} \mathrm{HB}, 100 \mathrm{nM}$ HC-Cy5, $100 \mathrm{nM}$ TH (S-TH or L-TH) and $25 \mathrm{nM}$ miR-21D (ratio 4:4:4:4:1). The excitation wavelength was $632 \mathrm{~nm}$, and the fluorescence spectra were collected from $650 \mathrm{~nm}$ to $750 \mathrm{~nm}$. 


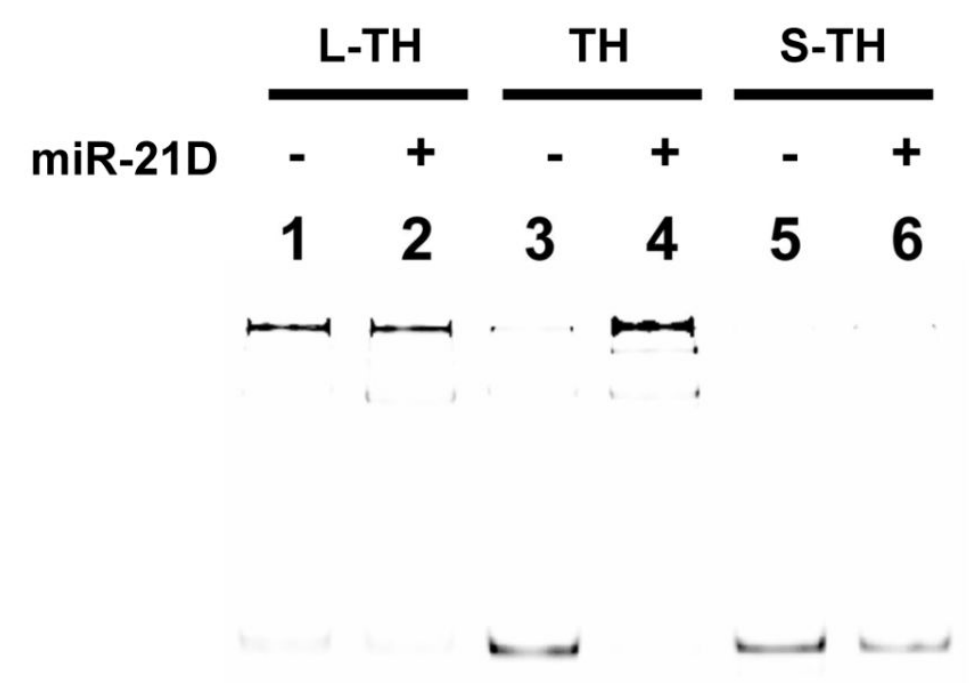

Figure S9. The nPAGE analysis to confirm the TH sequence-dependent NEPA assembly. The symbols, "+" and "--", indicate the presence and absence of the strands, respectively.

\section{Experimental procedure:}

The reaction solution was prepared to contain $800 \mathrm{nM} \mathrm{HA}, 800 \mathrm{nM} \mathrm{HB}, 800 \mathrm{nM}$ HC-Cy5, $800 \mathrm{nM}$ TH (or S-TH, or L-TH) and 200 $\mathrm{nM}$ miR-21D and the hybridization was allowed to proceed for $120 \mathrm{~min}$. Then, the nPAGE was run in $0.5 \times \mathrm{TBE}$ buffer at $80 \mathrm{~V}$ for $60 \mathrm{~min}$ to characterize the products. More details on the experiments are seen in Figure S4.

\section{Discussion:}

For the L-TH, the assembled DNA products with high molecular weight (MW) are clear observed regardless of target miR-21D, indicating the high background signal. On the contrary, for the S-TH, the addition of target species cannot cause the generation of assembled DNA products, indicating no detectable signal. Only the TH-based system is capable of sensing the existence of target molecules. Namely, for the TH, the assembled DNA products are generated only in the presence of target miR-21D. 


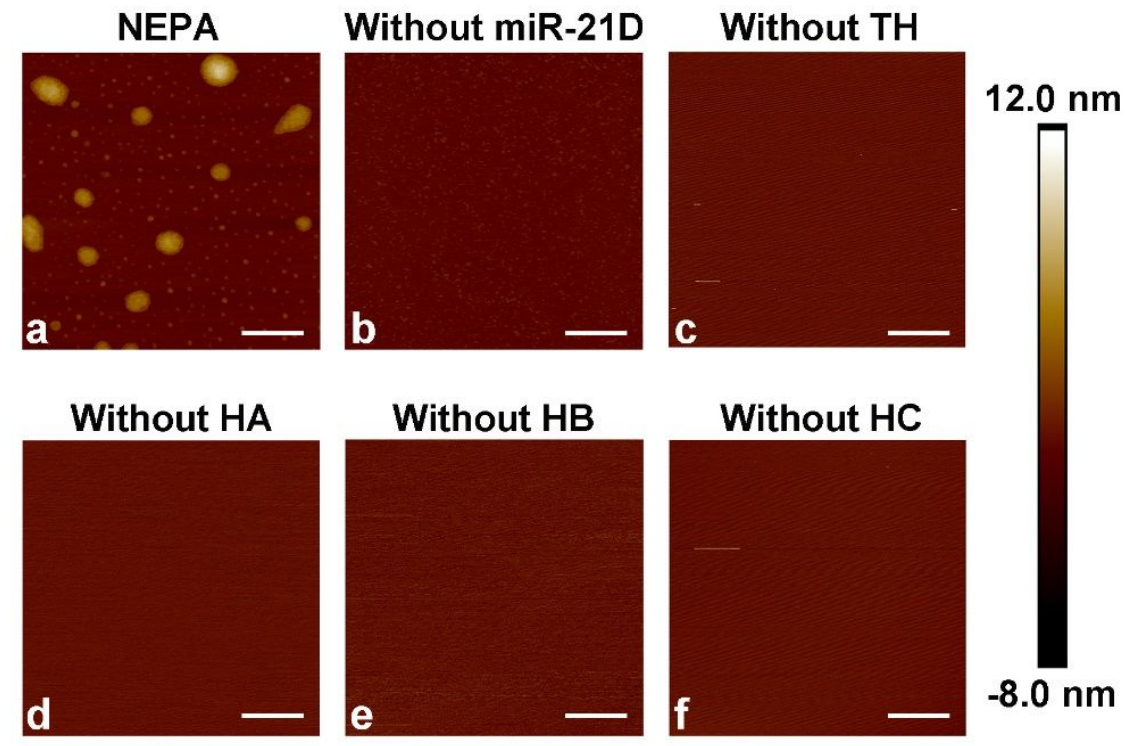

Figure S10. AFM images of NEPA-based assembled products in the presence of miR-21D (a), absence of miR-21D (b), TH (c), HA (d), HB (e) or HC (f). Image size: $2 \mu \mathrm{m} \times 2 \mu \mathrm{m}$. The scale bar is $400 \mathrm{~nm}$.

\section{Experimental procedure:}

The NEPA-based system in the presence (a) and absence of target miR-21D (b), TH (c), HA (d), HB (e) or HC (f) was prepared and incubated at $37^{\circ} \mathrm{C}$ for $120 \mathrm{~min}$ as described in the section of "METHODS". A 10- $\mu \mathrm{L}$ aliquot of sample was deposited onto the freshly cleaved mica surface, and kept for $15 \mathrm{~min}$ to achieve full adsorption. After the mica was carefully washed by PBS buffer and gently dried under a stream of nitrogen, AFM scanning was conducted in ScanAsyst mode on a MultiMode 8 atomic force microscope (Bruker, Germany). 


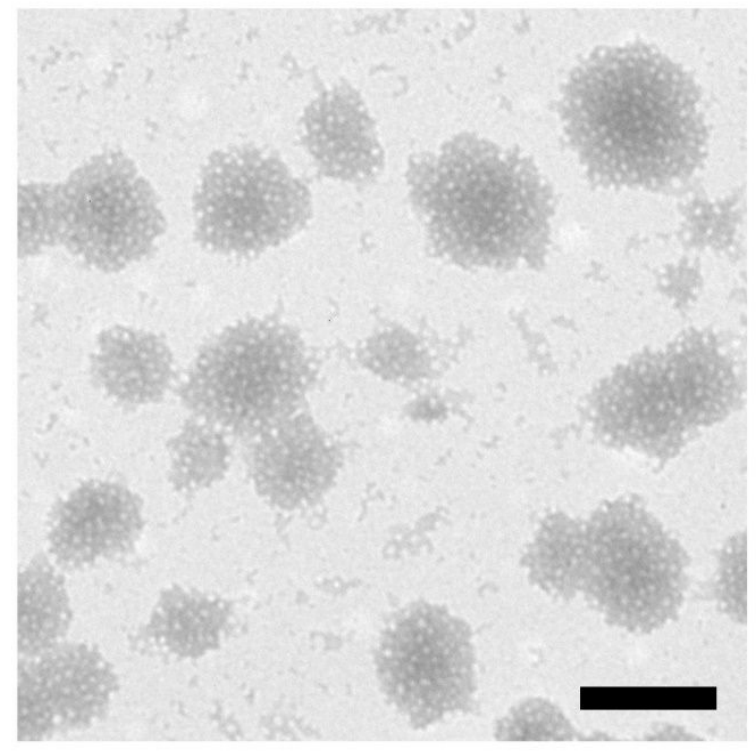

Figure S11. TEM image of NEPA-based assembled products in the presence of miR-21D. The scale bar is $200 \mathrm{~nm}$.

\section{Experimental procedure:}

The NEPA-based system in the presence of target miR-21D was prepared and incubated at $37^{\circ} \mathrm{C}$ for 120 min as described in the section of "METHODS". To conduct TEM analysis, a 10- $\mu \mathrm{L}$ aliquot of the freshly-prepared sample was diluted 20-fold with PBS, dropped onto amorphous carbon-coated copper grids, and then air-dried. TEM characterization was performed with a HT7700 transmission electron microscope (Hitachi Ltd., Japan). 


\section{DLS analysis}

DLS analysis shows that the average hydrodynamic diameter of NS superstructures is $204.1 \pm 27.8 \mathrm{~nm}$. The small peaks with the size of about $9.5 \mathrm{~nm}$ likely indicate a very small amount of assembled intermediates (less than $8 \%$ ). Although there is the slight difference in particle size between AFM and DLS, it is fairly reasonable because DNA building blocks are easily stretched in aqueous solution (for DLS), ${ }^{3}$ while the DNA assembled structures are collapsed under air-drying (for AFM). ${ }^{4}$

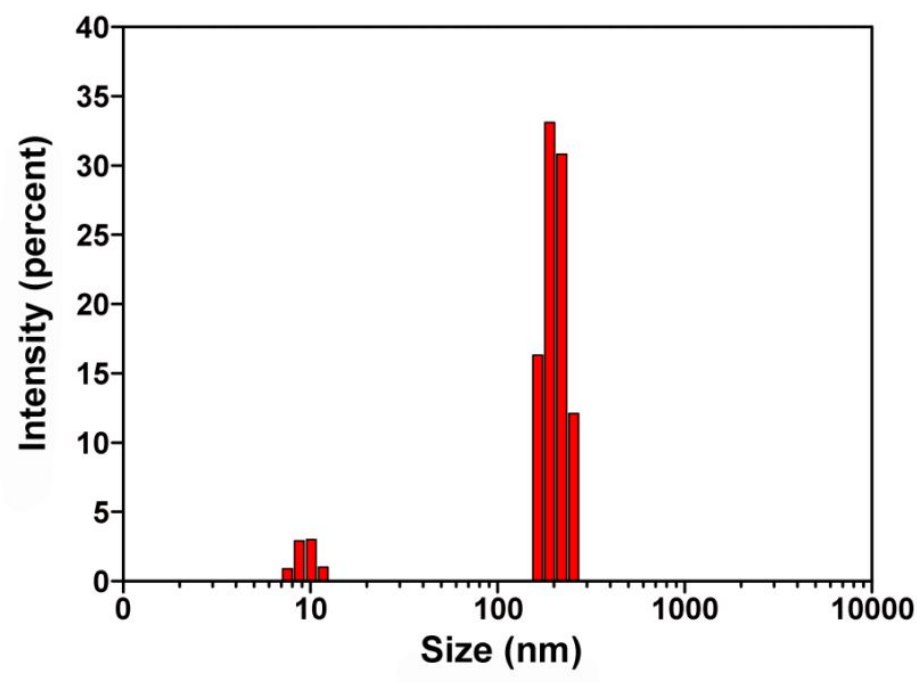

Figure S12. The average diameter of NEPA-based assembled products upon miR-21D estimated by Dynamic light scattering (DLS) measurement.

\section{Experimental procedure:}

The NEPA-based assembly induced by target miR-21D was carried out as described in the section of "METHODS". The resulting solution $(25 \mu \mathrm{L})$ was diluted to $1 \mathrm{~mL}$ with PBS buffer and then DLS measurement was performed on a Zetasizer Nano ZS (Malvern, $\mathrm{UK})$ at $25^{\circ} \mathrm{C}$. 


\section{Comparison of the fluorescence signal induced by target species between NEPA-based and FISH system}

Figure S13 provides the fully convincing evidence for NEPA-based signal amplification, where the same target species-induced fluorescence signal was detected as control under identical conditions by utilizing non-amplification one-to-one hybridization-based sensing system. One notices that, for NEPA-based system, the fluorescence signal gradually increases upon addition of target miR-21D over a very long period of time (more than $120 \mathrm{~min}$ ), which is in good agreement with the previously reported kinetics of toehold-mediated strand displacement (TSD). .-8 $^{5-2}$

For the TSD-based signal transduction, it possibly takes a relatively long time (e.g., $240 \mathrm{~min}$ ) for the signal to saturate especially at a low concentration of target species. ${ }^{5}$ In essence, NEPA-based assembly from HA, HB and HC upon the activation of locked TH in a target stimuli-responsive manner is a nonenzymatic strand-displacement reaction similar to the TSD process. Thus, the measured data are capable of confirming the signal amplification effect. However, the control sensing system shows a distinctly different signal transduction behavior: the fluorescence signal reaches a plateau within 15 min-incubation period, indicating a typical homogeneous one-to-one hybridization between MB and its complementary target DNA.9-10 Moreover, the maximal fluorescence intensity is only $30 \%$ lower than the signal detected from NEPA system.

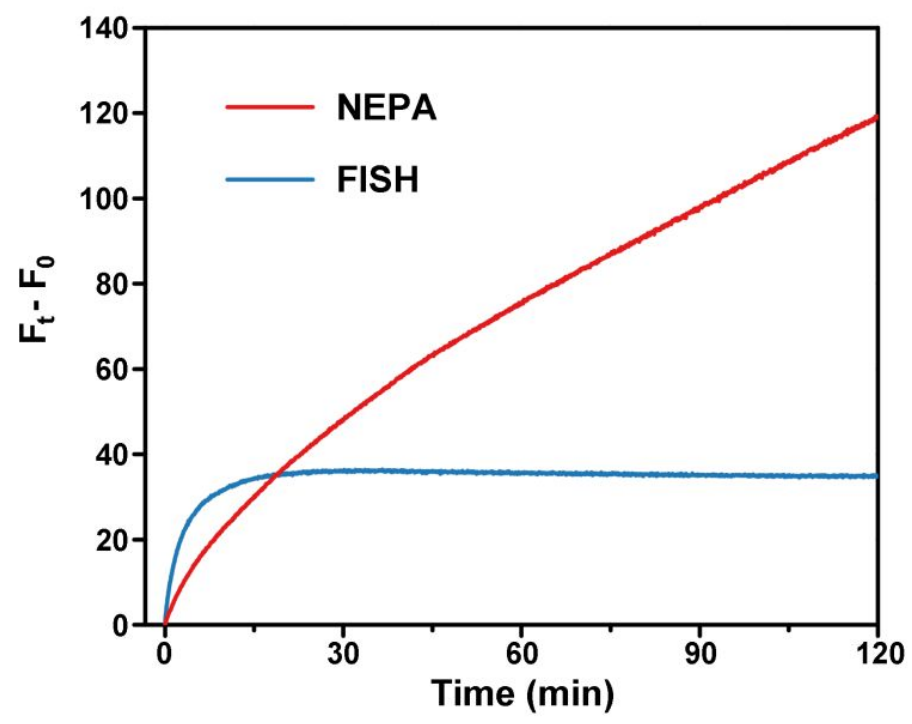

Figure S13. Comparison of the fluorescence signal induced by target species between NEPA-based and FISH system by real-time monitoring. $\mathrm{F}_{\mathrm{t}}$ and $\mathrm{F}_{0}$ indicate the fluorescence intensity in the presence and absence of target miR-21D.

\section{Experimental procedure:}

Real-time fluorescence monitoring during NEPA-based assembly: The DNA probes (each $2 \mu \mathrm{L}, 10 \mu \mathrm{M}$ ) were added to $150 \mu \mathrm{L}$ of PBS buffer, and then the solution volume was adjusted to $195 \mu \mathrm{L}$ with PBS buffer. After $5 \mu \mathrm{L}$ of $1 \mu \mathrm{M}$ target miR-21D was added, the fluorescent change was immediately monitored on a Hitachi F-7000 (Hitachi Ltd., Japan) with a Xenon lamp as the excitation source. The excitation wavelength was set as $632 \mathrm{~nm}$, and the emission wavelength was $660 \mathrm{~nm}$. The final concentrations of DNA probes and target species were as follows: $100 \mathrm{nM} \mathrm{HA}, 100 \mathrm{nM} \mathrm{HB}, 100 \mathrm{nM}$ HC-Cy5, $100 \mathrm{nM}$ TH and $25 \mathrm{nM}$ miR-21D (at a molar ratio of 4:4:4:4:1). 
Real-time fluorescence monitoring during FISH-based hybridization: TH-Cy5 $(2 \mu \mathrm{L}, 10 \mu \mathrm{M})$ was added to PBS buffer and adjusted to $195 \mu \mathrm{L}$. After $5 \mu \mathrm{L}$ of $1 \mu \mathrm{M}$ target miR-21D was added, the fluorescent change was immediately monitored under identical conditions to NEPA process. The final concentrations of TH-Cy5 and miR-21D in the reaction solution $(200 \mu \mathrm{L})$ were $100 \mathrm{nM}$ and $25 \mathrm{nM}$, respectively (at a molar ratio of 4:1). 
a

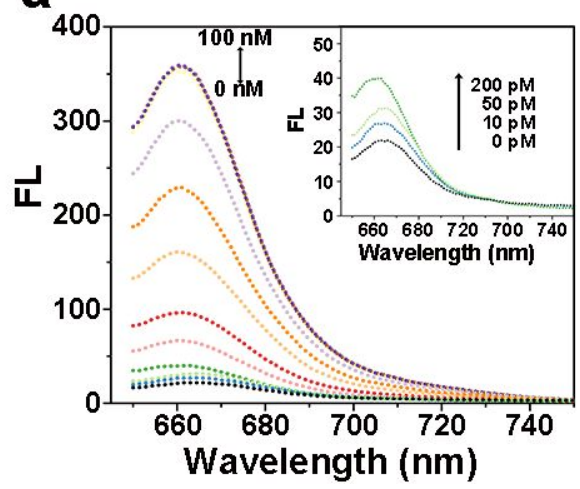

b

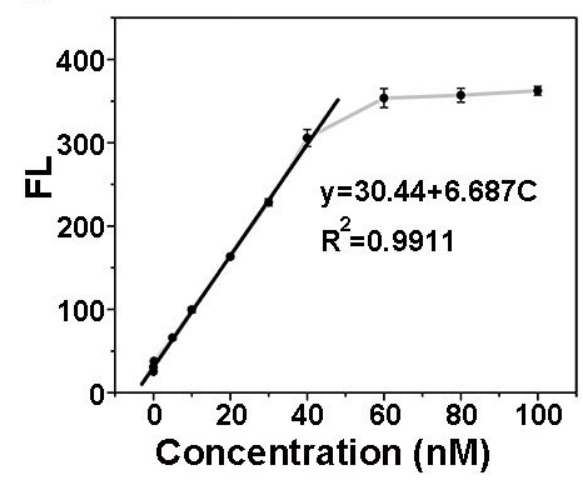

Figure S14. Capability of NEPA-based system to sense target species. (a) The fluorescence spectrum in the presence of target species at different concentrations. (b) The linear relationship between the fluorescence intensity and target miR-21D concentration. Error bars represent the standard deviations of at least three independent measurements.

\section{Experimental procedure:}

A $25-\mu \mathrm{L}$ PBS buffer-based solution was prepared to contain the same concentration of HA, HB, HC-Cy5 and TH, and a given concentration of target miR-21D. After incubation at $37^{\circ} \mathrm{C}$ for $120 \mathrm{~min}$, the resulting solutions were diluted to $200 \mu \mathrm{L}$ with PBS buffer, followed by fluorescence spectroscopic analysis. The final concentration of HA, HB, HC-Cy5 and TH was $100 \mathrm{nM}$, while the final concentration of target miR-21D is $0,10 \mathrm{pM}, 50 \mathrm{pM}, 100 \mathrm{pM}, 5 \mathrm{nM}, 10 \mathrm{nM}, 20 \mathrm{nM}, 30 \mathrm{nM}, 40 \mathrm{nM}, 60 \mathrm{nM}, 80 \mathrm{nM}$ or 100 $\mathrm{nM}$. The linear response range is from $10 \mathrm{pM}$ to $40 \mathrm{nM}$ with the detection limit of $1.4 \mathrm{pM}(\mathrm{S} / \mathrm{N}=3)$. More details are seen in Section A2.2. 
a

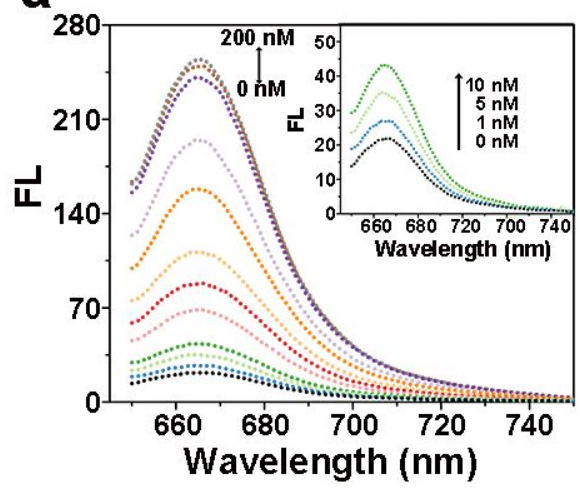

b

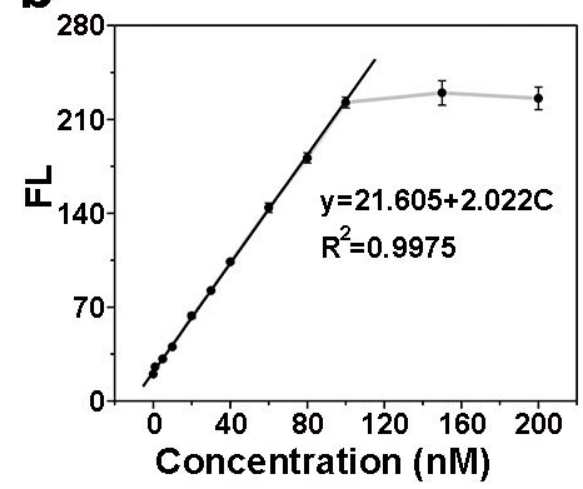

Figure S15. Capability of FISH-based system to sense target species. (a) The fluorescence spectra in the presence of target species at different concentrations. (b) The linear relationship between the fluorescence intensity and target miR-21D concentration. Error bars represent the standard deviations of at least three independent measurements.

\section{Experimental procedure:}

The reaction solution was prepared by adding TH-Cy5 and target miR-21D into PBS buffer and adjusting its volume to $25 \mu \mathrm{L}$. After incubation at $37^{\circ} \mathrm{C}$ for $120 \mathrm{~min}$, the resulting solutions were diluted to $200 \mu \mathrm{L}$ with PBS buffer, followed by fluorescence spectroscopic analysis. TH-Cy 5 concentration is $100 \mathrm{nM}$. The final concentration of target miR-21D is $0,1 \mathrm{nM}, 5 \mathrm{nM}, 10 \mathrm{nM}, 20$ $\mathrm{nM}, 30 \mathrm{nM}, 40 \mathrm{nM}, 60 \mathrm{nM}, 80 \mathrm{nM}, 100 \mathrm{nM}, 150 \mathrm{nM}$ or $200 \mathrm{nM}$. The linear response range is from $1 \mathrm{nM}$ to $100 \mathrm{nM}$ and the detection limit is $133.4 \mathrm{pM}(\mathrm{S} / \mathrm{N}=3)$. 


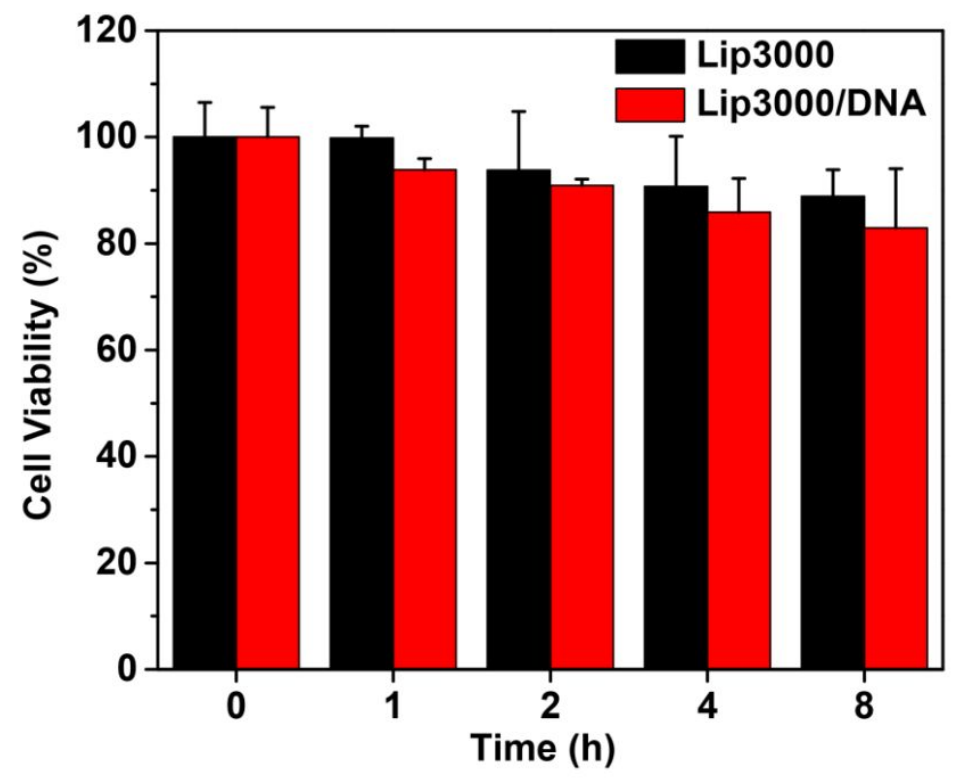

Figure S16. The biocompatibility of NEPA-based system by MTT assay to determine cell viability of HeLa cells treated with Lip3000/DNA probes for different periods $(0 \mathrm{~h}, 1 \mathrm{~h}, 2 \mathrm{~h}, 4 \mathrm{~h}$ and $8 \mathrm{~h})$ at $37^{\circ} \mathrm{C}$. Error bars represent the standard deviations of at least three independent measurements.

\section{Experimental procedure:}

Cell viability assay: HeLa cells were pre-incubated on 96-well plates (about $10^{4}$ cells per well) for the MTT assay. Cells were transfected with Lip3000/DNA probes (HA, HB, HC and TH) for given time points $(0 \mathrm{~h}, 1 \mathrm{~h}, 2 \mathrm{~h}, 4 \mathrm{~h}$ and $8 \mathrm{~h})$ at $37^{\circ} \mathrm{C}$. The cells treated only with Lip3000 were used as controls. More details are seen in Section A2.4.

For the MTT assay, an MTT stock solution was diluted by RPMI-1640 medium (phenol red-free) to $0.5 \mathrm{mg} / \mathrm{mL}$. Then, the medium in every well was replaced with $100 \mu \mathrm{L}$ of MTT diluent, followed by incubation for $4 \mathrm{~h}$ at $37^{\circ} \mathrm{C}$. The cells were lysed with $100 \mu \mathrm{L}$ of dimethyl sulfoxide after removing the MTT diluent. Absorbance was recorded at $570 \mathrm{~nm}$ on an Infinite M200 PRO microplate reader (TECAN, Switzerland).

\section{Discussion:}

As cytotoxicity is a definite concern for biomedical applications, standard MTT assay was performed for quantitative testing of the viability of HeLa cells treated with Lip3000/DNA probes. As shown in Figure S16, no significant cytotoxicity or side effect is found in living cells. These results confirmed that NEPA system can be used to detect specific intracellular microRNAs with good biocompatibility. 


\section{Optimal incubation time for the intracellular NEPA assembly}

Reaction time for the intracellular NEPA assembly was optimized to efficiently enhance the optical signal. As shown in Figure S17, S18 and S19, the fluorescent imaging of individual cells and flow cytometric analysis of a population of cells demonstrate that an obvious fluorescence signal of HC-Cy5 is detected after incubation for 150 (or 160) min. With futher increasing the incubation time, the fluorescence signal increases rapidly and plateaus at its maximum fluorescence value after 220-min incubation, indicating that NEPA reaction reaches the equilibrium.
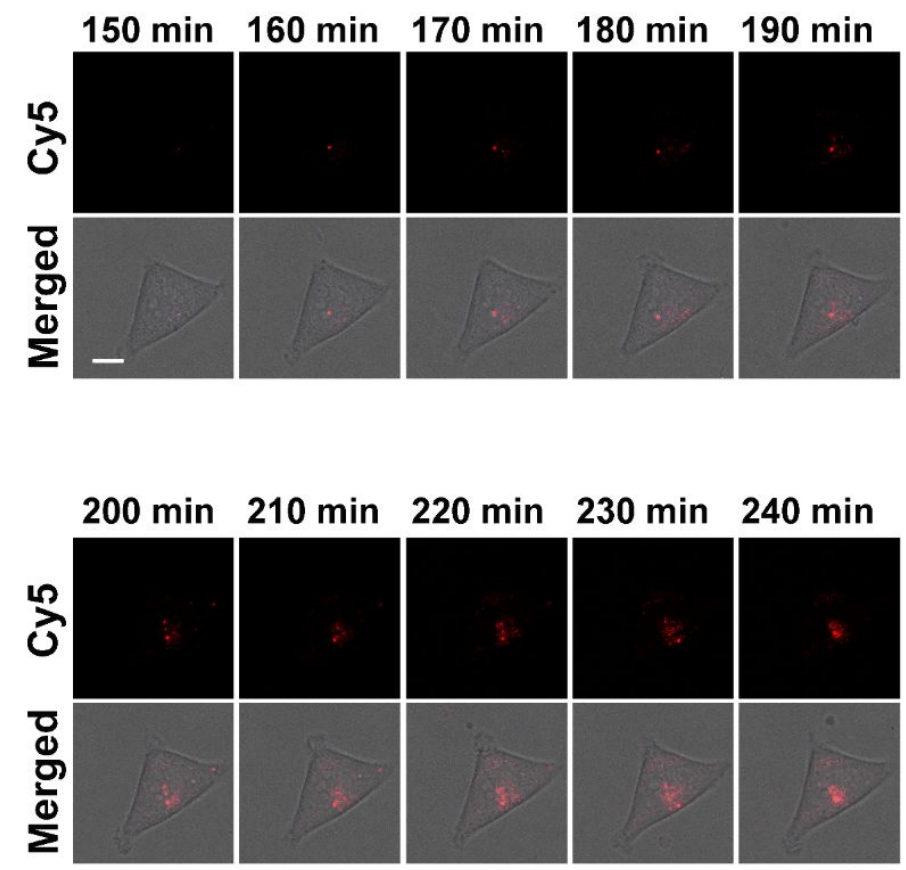

Figure S17. Real-time fluorescence monitoring of NEPA-based assembly progress inside HeLa cells. The red fluorescence represents NEPA-based assembled products, DNA NS containing the opened Cy5-labeled HC probes. Scale bar, $10 \mu \mathrm{m}$.

\section{Experimental procedure:}

NEPA-based real-time fluorescence imaging of HeLa cells: HeLa cells were cultured, transfected with DNA probes and imaged by the same procedure as that adopted in Section A2.6, but a label-free TH was used instead. During the whole real-time confocal imaging, the cells were placed in a humid atmosphere with $5 \% \mathrm{CO}_{2}$ at $37^{\circ} \mathrm{C}$. 

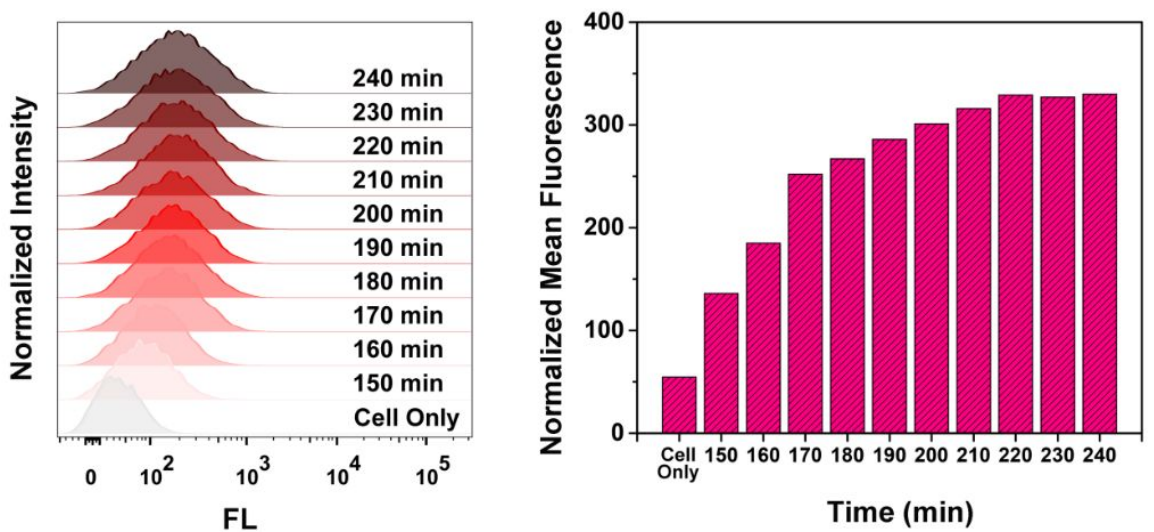

Figure S18. Flow cytometric analysis of HeLa cells incubated with Lip3000/NEPA probes at different time points (left panel) and the corresponding normalized mean fluorescence intensity (right panel). The final concentration of HA, HB, HC-Cy5 and TH in transfection solution is $50 \mathrm{nM}$.

\section{Experimental procedure:}

HeLa cells were plated on a 6-well plastic-bottom plate and cultured in complete DMEM medium for $24 \mathrm{~h}$ at $37{ }^{\circ} \mathrm{C}$ in a humidified incubator with $5 \% \mathrm{CO}_{2}$. When grown to $70 \sim 80 \%$ confluency, the cells were washed thrice with PBS buffer, followed by transfection of NEPA probes with the help of transfection agent, Lip3000, for given time periods. The transfection solution was prepared by adding different probes (HA, HB, HC-Cy5 and TH-FAM, each $5 \mu \mathrm{L}, 10 \mu \mathrm{M}$ ) and Lip3000 into Opti-MEM medium, and the solution volume was adjusted to $1000 \mu \mathrm{L}$ according to the instruction. The final concentration of each DNA probe is $50 \mathrm{nM}$. After washing, digestion by trypsin, centrifugation and re-suspending in PBS buffer, the flow cytometric analysis was performed. More details are seen in Section A2.5. 


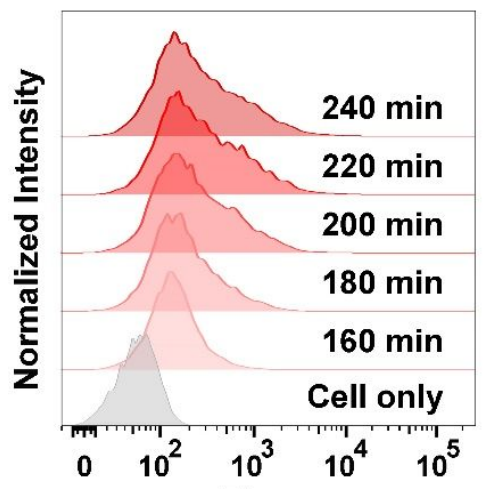

FL

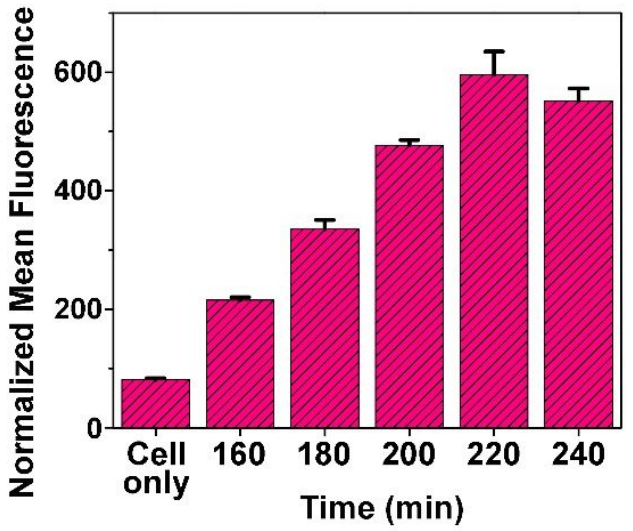

Figure S19. Flow cytometric analysis of MCF-7 cells incubated with Lip3000/NEPA probes at different time points (left panel) and the corresponding normalized mean fluorescence intensity (right panel). The final concentration of HA, HB, HC-Cy5 and TH in transfection solution is $50 \mathrm{nM}$. Error bars represent the standard deviations of at least three independent measurements.

\section{Experimental procedure:}

MCF-7 cells were plated on a 6-well plastic-bottom plate and cultured in complete DMEM medium for $24 \mathrm{~h}$ at $37{ }^{\circ} \mathrm{C}$ in a humidified incubator with $5 \% \mathrm{CO}_{2}$. When grown to $70 \sim 80 \%$ confluency, the cells were washed thrice with PBS buffer, followed by transfection of NEPA probes with the help of transfection agent, Lip3000, for given time periods. The transfection solution was prepared by adding different probes (HA, HB, HC-Cy5 and TH-FAM, each $5 \mu \mathrm{L}, 10 \mu \mathrm{M}$ ) and Lip3000 into Opti-MEM medium, and the solution volume was adjusted to $1000 \mu \mathrm{L}$ according to the instruction. The final concentration of each DNA probe is $50 \mathrm{nM}$. After washing, digestion by trypsin, centrifugation and re-suspending in PBS buffer, the flow cytometric analysis was performed. More details are seen in Section A2.5. 
a

\section{Opening in Bitmap (BMP) with MATLAB}
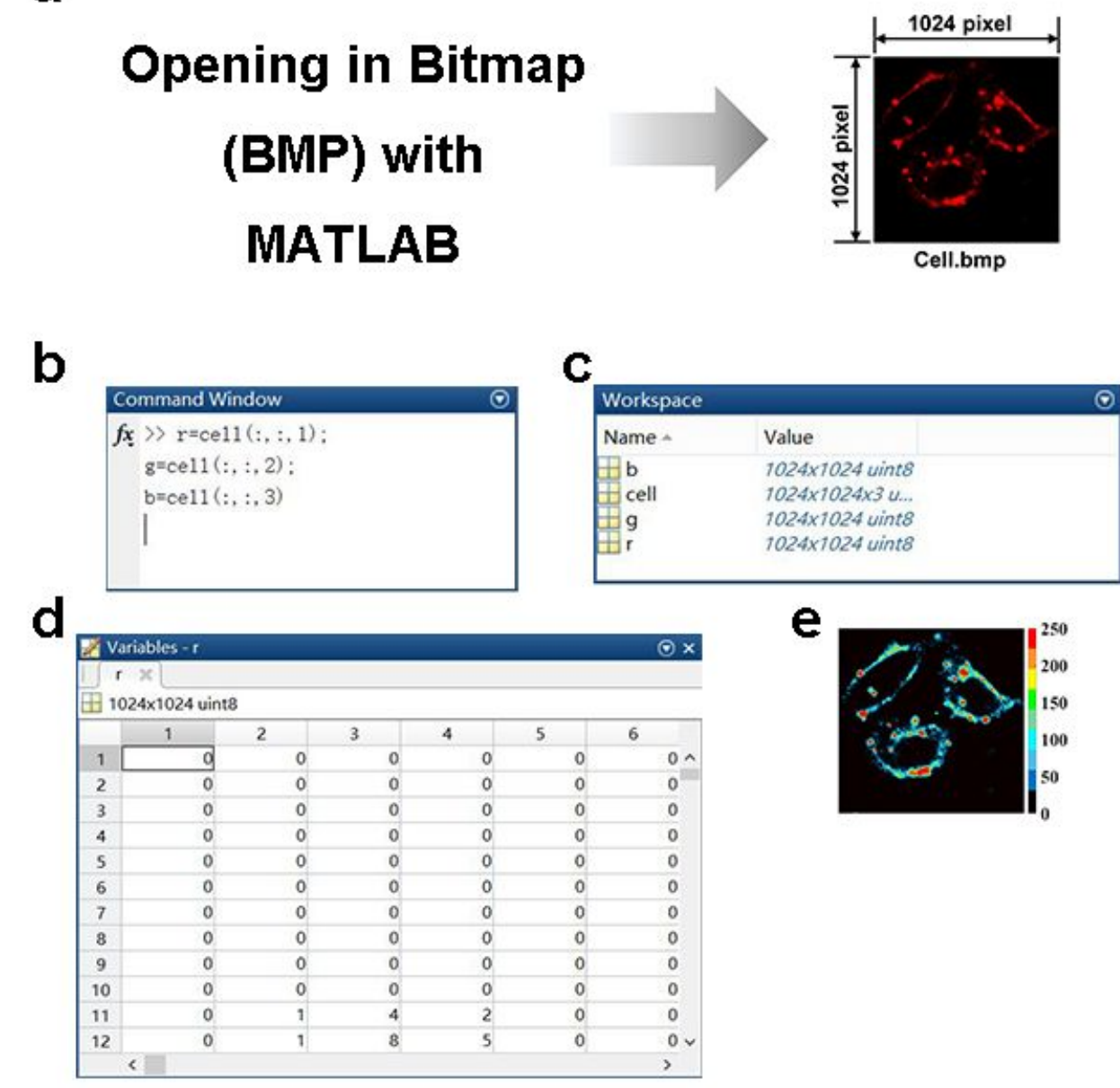

Figure S20. Method to extract two-dimensional data of fluorescence intensities from cell images by MATLAB. (a) Cell image by opening the typical fluorescence image of MCF-7 cells (red channel for Cy5) in Bitmap (BMP) with MATLAB. (b) Two-dimensional matrix containing the fluorescence intensity information of three color-channels (R: red, G: green, and B: blue) converted from BMP image of the cell. (c) Matrixes generated in workspace. (d) The two-dimensional form of the red channel. (e) Distribution image of the intensity of red channel represented in (a). 


\section{Quantitative PCR (q-PCR) assay of miR-21}

Since quantitative reverse transcription polymerase chain reaction (qRT-PCR) is considered to be a gold standard with the high sensitivity and good universality for miRNA analysis, ${ }^{11-13}$ the miR-21 expression level in intact MCF-7, $\mathrm{E}_{2}$-treated MCF-7 and L-02 cells was evaluated by qRT-PCR. The results are shown in Figure S21.

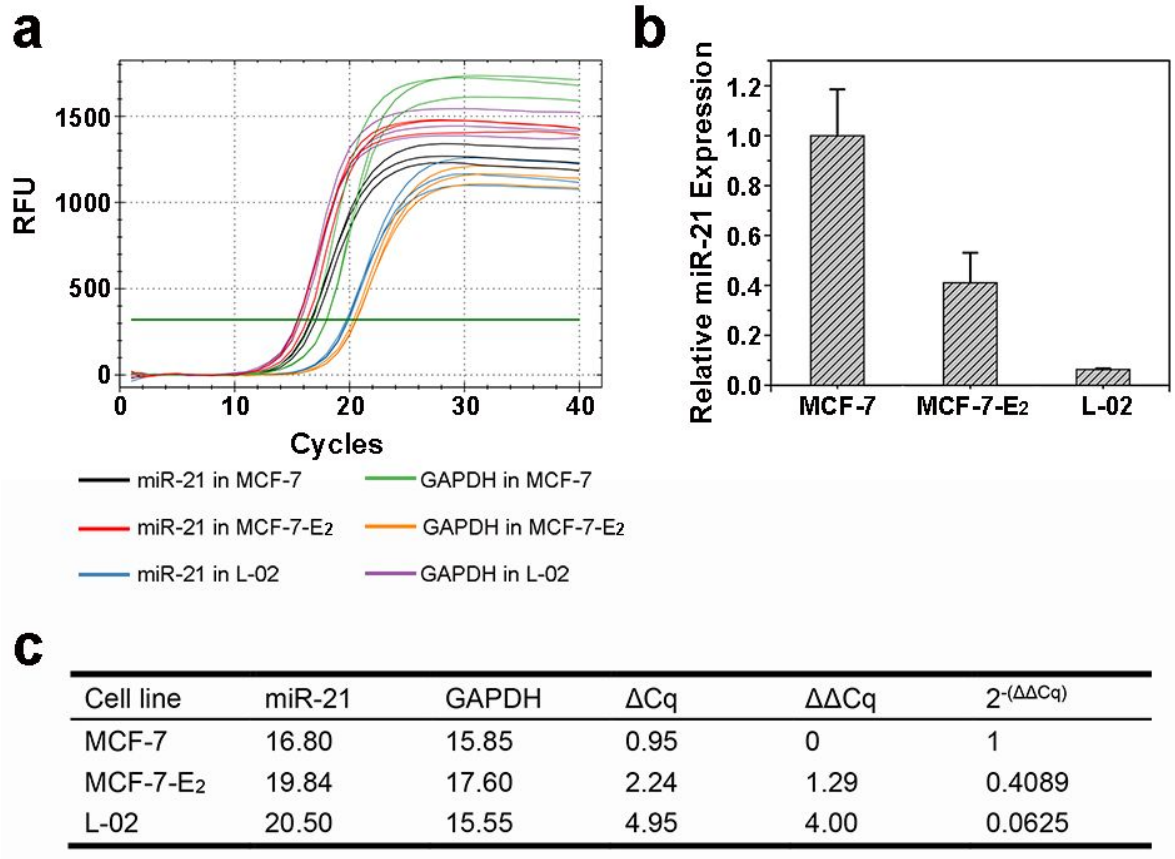

Figure S21. (a) Quantitative PCR (q-PCR) curves for miRNA-21 and GAPDH RNA extracted from MCF-7 cells ( $E_{2}$-treated or untreated) and L-02 cells. (b) The relative miR-21 expression level in MCF-7 cells, $\mathrm{E}_{2}$-treated MCF-7 cells (MCF-7-E $\mathrm{E}_{2}$ ) and L-02 cells. Error bars represent the standard deviations of three independent measurements. (c) Average Cq value in q-PCR assay of

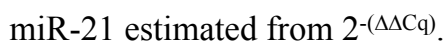

\section{Experimental procedure:}

$M C F-7-E_{2}$ preparation: MCF-7 cells were incubated in $400 \mu \mathrm{L}$ of complete DMEM medium contaning $10 \mathrm{nM}$ Estradiol $\left(\mathrm{E}_{2}\right)$ for 24 h. More details are provided in Section A2.4.

MiRNAs Extraction: Cells were lysed with Trizol Reagent Kit (Invitrogen) according to the instructions. The resulting RNA solutions were stored at $-80^{\circ} \mathrm{C}$ before use.

qRT-PCR analysis: The qRT-PCR experiments were performed according to the instruction by PrimeScriptTM RT reagent Kit (TaKaRa). GAPDH was regarded as the internal reference. The sequences used in qPCR are shown in Table S1. Relative expression level was determined using the comparative threshold cycle $(\mathrm{Cq})$ method. 


\section{Fluorescence imaging of miRNAs in other live cells}

In order to further explore the ability to fluorescently image the intracellular target RNA at different expression levels, the NEPA-based assembly was performed in Human cervical cancer cell lines (HeLa) that expresses the miR-21 at the lower level than MCF-7 cells. ${ }^{14-15}$ Moreover, L-02 cells were used as negative control. As shown in Figure S22, no obvious fluorescence signal is detected in L-02 cells, but an obvious signal can be easily detected in HeLa cells. The results from confocal microscopy measurement were also validated by flow cytometry (Figure S23). Moreover, if TH-FAM is not cotransfected into HeLa cells, the NEPA system fails to image miR-21 because NEPA assembly cannot occur, which is intuitively confirmed by a fact that no the fluorescence of both FAM and Cy5 is detected in both confocal images (Figure S24) and flow cytometry assay (Figure S25).

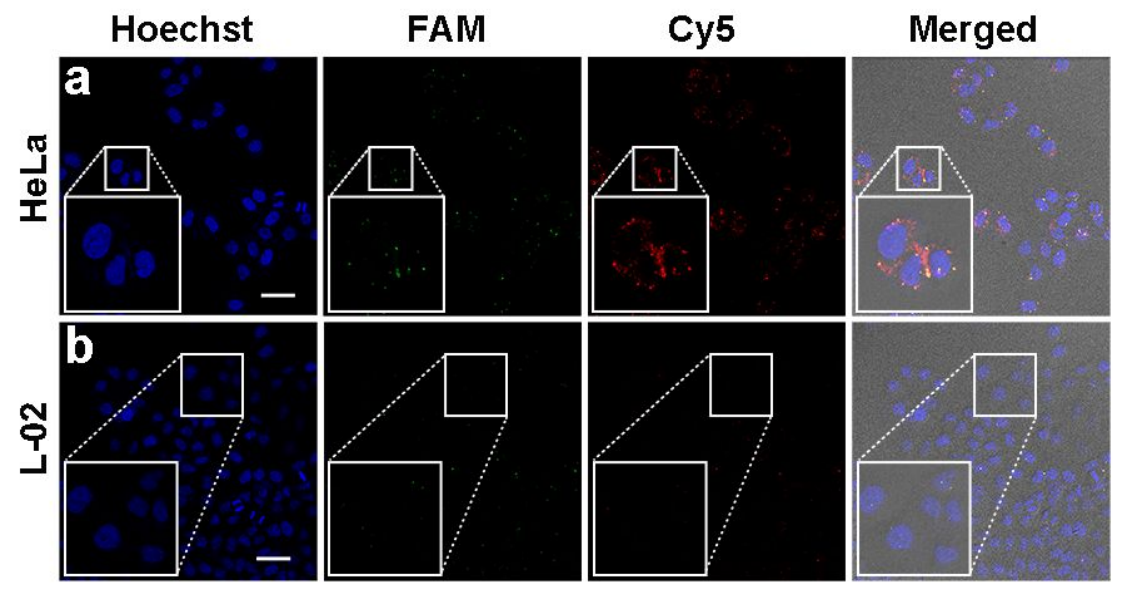

Figure S22. Confocal imaging to validate the feasibility of NEPA-based system for the miR-21 detection in other live cells of interest. Fluorescence images of HeLa cells (a) and L-02 cells (b) provide the comparative evaluation. The green and red colors represent FAM fluorescence and Cy5 fluorescence, respectively. The scale bar is $50 \mu \mathrm{m}$.

\section{Experimental procedure:}

Cell imaging experiments were performed using a similar procedure described in the section of "METHODS". Specifically, the cells were cultured on the 12-well plastic-bottom plate coverslips for $24 \mathrm{~h}$. When grown to $70 \sim 80 \%$ confluency and washed thrice with PBS buffer, the cells were incubated in $400 \mu \mathrm{L}$ of Opti-MEM medium containing Lip3000 and required DNA probes, including HA, HB, HC-Cy5 and TH-FAM (each $2 \mu \mathrm{L}, 10 \mu \mathrm{M}$ ), which was prepared according to the instruction. The final concentration of the four probes was $50 \mathrm{nM}$. After kept at $37^{\circ} \mathrm{C}$ for $220 \mathrm{~min}$, the cells were washed thrice with PBS buffer and then fixed in $4 \%$ polyformaldehyde for $15 \mathrm{~min}$. Before confocal imaging, the cell nuclei were stained by incubating in $500 \mu \mathrm{L}$ of 12.5 $\mu \mathrm{g} / \mathrm{mL}$ Hoechst 33342 solution for $15 \mathrm{~min}$ and then washed thrice with PBS buffer. Finally, the coverslips were separately treated as follows: the anti-fluorescence quenching sealing agents were added to a rectangular slide, then the coverslip was inverted onto the rectangular slide, and the cells on the coverslip were imaged on a Leica SP8 laser scanning confocal microscope (Leica, Germany). 

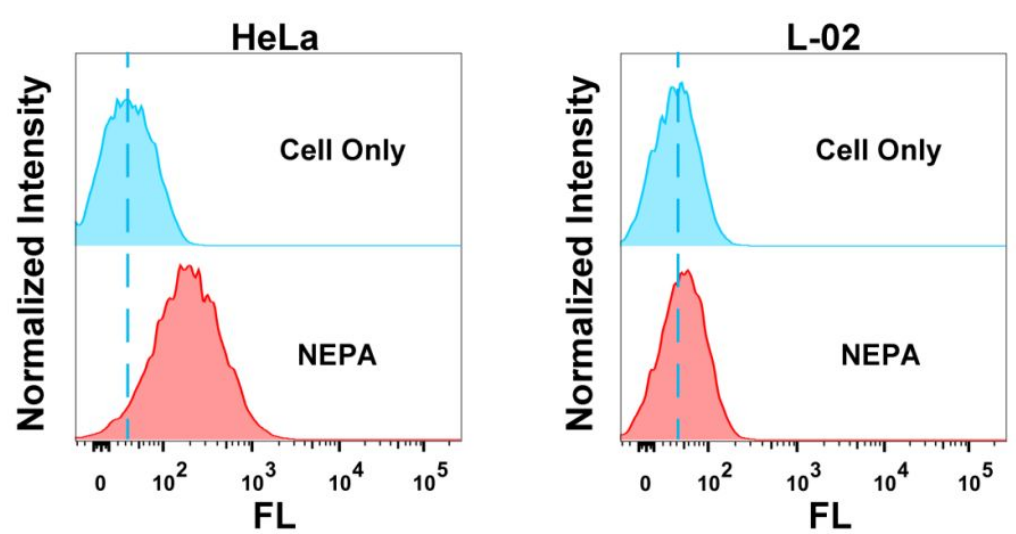

Figure S23. Flow cytometric analysis of HeLa cells (left panel) and L-02 cells (right panel) treated with transfection solution containing NEPA probes (HA, HB, HC-Cy5 and TH-FAM, each $50 \mathrm{nM}$ ).

\section{Experimental procedure:}

The flow cytometric analyses, including cell culture, transfection with NEPA probes and flow cytometric assay, were performed using the similar procedure to that described in Figure S18. Specifically, Cells were cultured in the corresponding medium for $24 \mathrm{~h}$ on the 6-well plastic-bottom plate coverslips. When grown to $70 \sim 80 \%$ confluency, the cells were washed thrice with PBS buffer and incubated in transfection solution that was prepared by adding different probes (HA, HB, HC-Cy5 and TH-FAM, each $5 \mu \mathrm{L}, 10$ $\mu \mathrm{M})$ and Lip3000 into Opti-MEM medium and adjusting the volume to $1000 \mu \mathrm{L}$ according to the instruction. The final concentration of the four DNA probes is $50 \mathrm{nM}$. After kept at $37{ }^{\circ} \mathrm{C}$ for $220 \mathrm{~min}$, the cells were washed thrice with PBS buffer, separated by trypsin digestion and re-suspended in $1000 \mu \mathrm{L}$ of PBS buffer. Finally, flow cytometric analysis was conducted on a BD FACSAria flow cytometry (BD Biosciences, USA). 


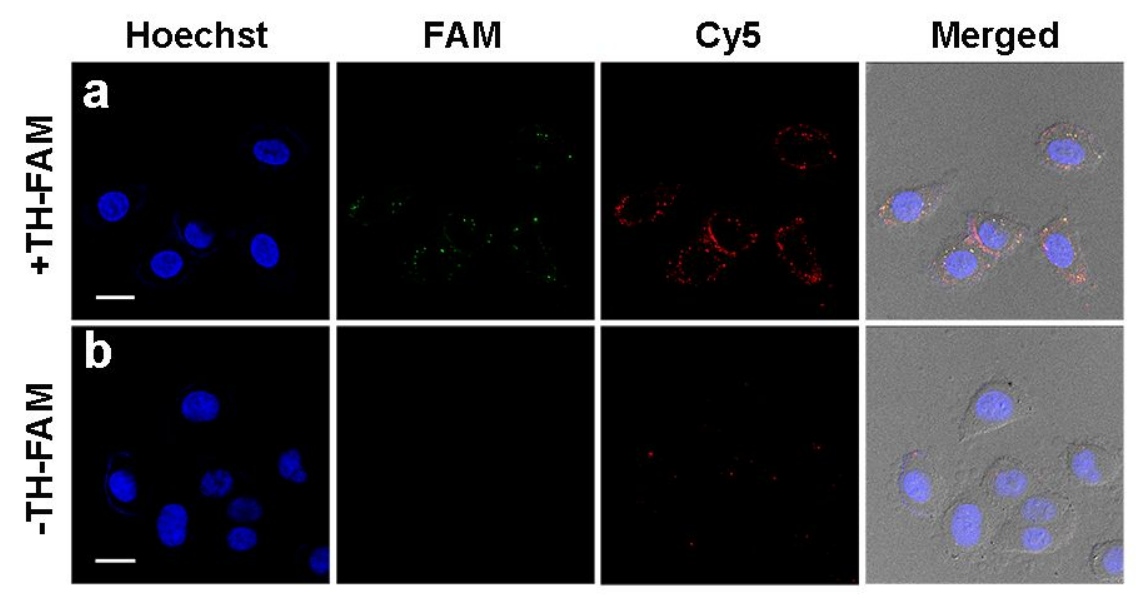

Figure S24. TH probe-dependent confocal fluorescence imaging of live cells. Fluorescence images of HeLa cells treated with the mixture of HA, HB and HC-Cy5 in the presence (a) and absence (b) TH-FAM. The green and red colors represent FAM fluorescence and Cy5 fluorescence, respectively. The scale bar is $25 \mu \mathrm{m}$.

\section{Experimental procedure:}

The cell imaging experiments were performed according to the similar procedure to that described in Figure S22, but TH-FAM was not employed in panel (b). 


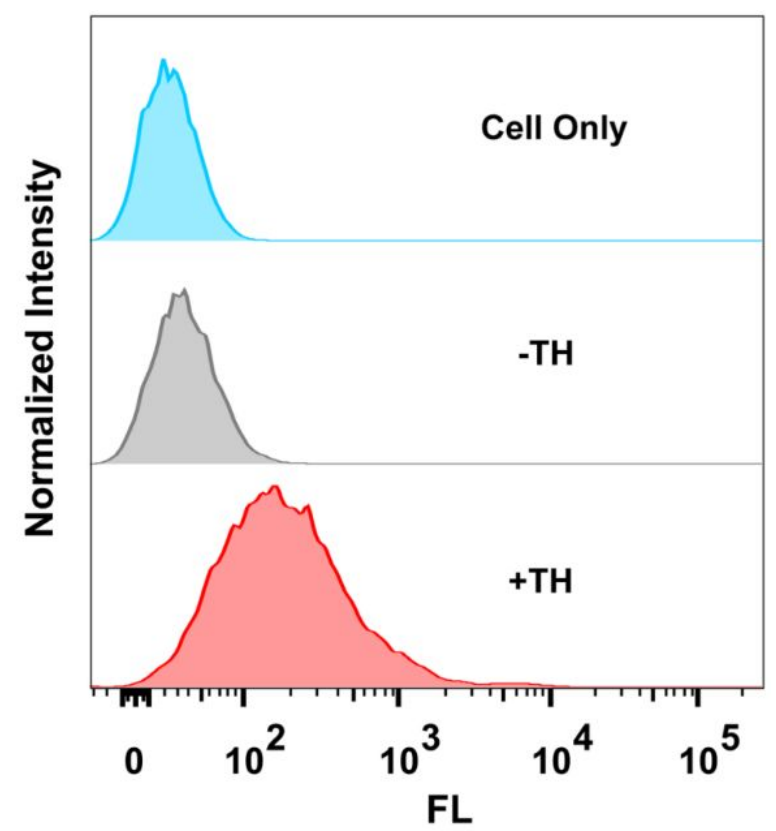

Figure S25. Flow cytometry analysis of NEPA assembly within HeLa cells transfected with the mixture of HA, HB and HC-Cy5 in the presence (a) and absence (b) TH. The final concentration of each DNA probe is $50 \mathrm{nM}$.

\section{Experimental procedure:}

Cells were cultured on the 6-well plastic-bottom plate coverslips for $24 \mathrm{~h}$. After grown to $70 \sim 80 \%$ confluency and washed thrice with PBS buffer, the cells were incubated in $1000 \mu \mathrm{L}$ of transfection solution that was prepared by mixing different probes with Lip3000 in Opti-MEM medium according to the instruction. The final concentration of each DNA probe is $50 \mathrm{nM}$. "+TH" indicates that the transfection solution has an equal amount of HA, HB, HC-Cy5 and TH-FAM, while "-TH" indicates to have an equal amount of HA, HB and HC-Cy5 but without TH-FAM. After kept at $37{ }^{\circ} \mathrm{C}$ for $220 \mathrm{~min}$, the cells were washed thrice with PBS buffer, separated by trypsin digestion and re-suspended in PBS buffer. Finally, the samples were analyzed by a BD FACSAria flow cytometry (BD Biosciences, USA). A $633 \mathrm{~nm}$ laser was used as exciting source to measure the fluorescence intensity of Cy5, and the cells without any treatment were used as the control. 


\section{Relationship between intracellular miRNA content and NEPA assembly-mediated fluorescence signal intensity}

To directly evaluate whether NEPA system can be used to screen the different expression levels of miRNA in different cell lines, MCF-7, HeLa and L-02 cells were separately transfected with NEPA probes under identical conditions, followed by flow cytometric analysis. As shown in Figure S26a and S26b, the fluorescence signal increases in the order: L-02 $<$ HeLa $<$ MCF-7, which agrees well with the previously-reported data. ${ }^{14}$ These experimental results demonstrate that NEPA assembly-mediated fluorescence signal is dependent on the content of miRNA trigger within living cells.

\section{No substantial difference in transfection efficiency between different cell lines}

To explore whether the transfection efficiencies between different cell lines are different from each other, random fluorescently-labeled DNA, Random DNA-Cy5, was separately transfected into MCF-7, HeLa and L-02 cells, and the transfection efficiency was estimate by flow cytometric assay. As shown in Figure S26c and S26d, compared with MCF-7, the transfection efficiency of DNA probes into L-02 is not compromised, and HeLa cells display the slightly-increased transfection efficiency. Clearly, the NEPA assembly-induced fluorescence signal intensity is determined by the expression level of intracellular miRNA rather than by the transfection efficiency of NEPA probes.
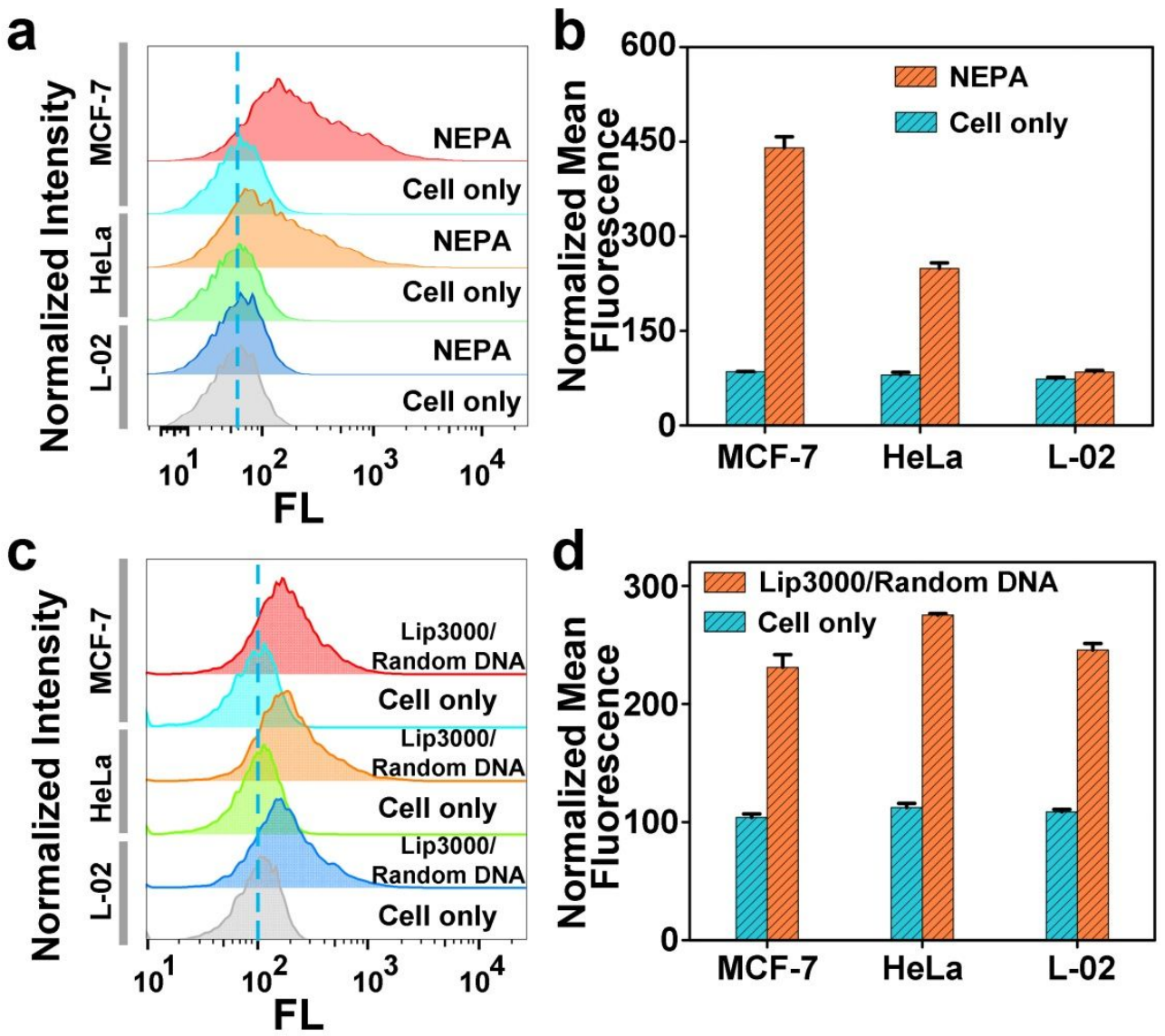

Figure S26. Relationship between intracellular miRNA content and NEPA assembly-mediated fluorescence signal intensity. (a) Flow cytometric analysis of MCF-7, HeLa and L-02 cells treated with transfection solution containing NEPA probes (HA, HB, HC-Cy5 and TH-FAM, each $50 \mathrm{nM}$ ). (b) Representative histograms of fluorescence signal recorded from (a). (c) Flow cytometric analysis of MCF-7, HeLa and L-02 cells treated with transfection solution containing Random DNA-Cy5 (50 nM). (d) 
Representative histograms of fluorescence signal recorded from (c). The cells without transfected with DNA probes were used as the control.

\section{Experimental procedure:}

The flow cytometric analyses, including cell culture, transfection with random probes and flow cytometric assay, were performed using the similar procedure to that described in Figure S18. However, for panel $\mathrm{c}$ and panel d, Random DNA-Cy5 was used instead of NEPA probes. More details are described in the section of "METHODS". 

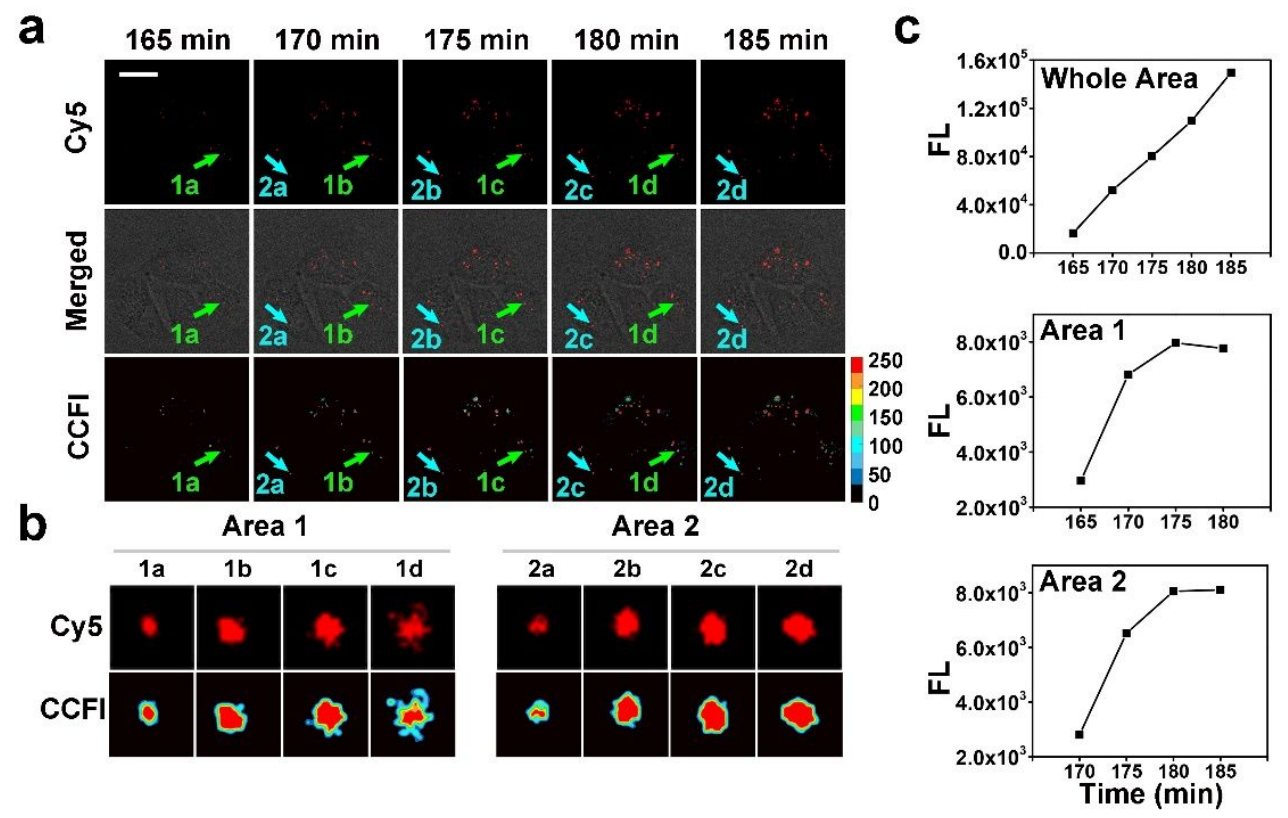

Figure S27. The real-time fluorescence monitoring of NEPA-based assembly process in the wide field of view. (a) Lifetime study of NEPA products formed in live HeLa cells. The red dots represent DNA nanospheres with Cy5-labeled probes. Merged image indicates fluorescence image merged with differential interference contrast (DIC) microscopy-based images. (b) Amplified red dots marked in panel (a) in given areas. Scale for both Area 1 and Area 2 is $4.0 \times 4.0 \mu \mathrm{m}$. (c) Incubation time-dependent fluorescence intensity of the whole area of panel (a) and its local areas shown in panel (b). Fluorescence intensity of Cy5 is estimated with Image $\mathrm{J}$ software. Scale bar is $20 \mu \mathrm{m}$.

\section{Experimental procedure:}

The real-time fluorescence analysis, including cell culture, transfection with NEPA probes and real-time fluorescence analysis, were performed using the same procedure as Figure 3a. More details are seen in the section of "METHODS". 


\section{Real-time fluorescence monitoring of NEPA-based assembled products formed within MCF-7 cells}

The formation of NEPA-based NS products within MCF-7 cells is also monitored in real-time. Figure S28 shows the dynamic changes in the fluorescence signal from "Cy5" images. Most of fluorescent spots become brighter (e.g., in Areas 2) with the increment of incubation time, and some new fluorescent spots appear (e.g., in Area 2). However, a few spots become darker (e.g., Sub-Area 1 in dotted ring indicated by yellow arrow) owing to the enzymatic degradation. Although the changes in fluorescence spots in different areas (including Sub-Area 1) are different from each other, the fluorescence intensity of cells, especially in the whole area, gradually increases with the increment of incubation time, indicating that DNA NS nanostructures are progressively grown.

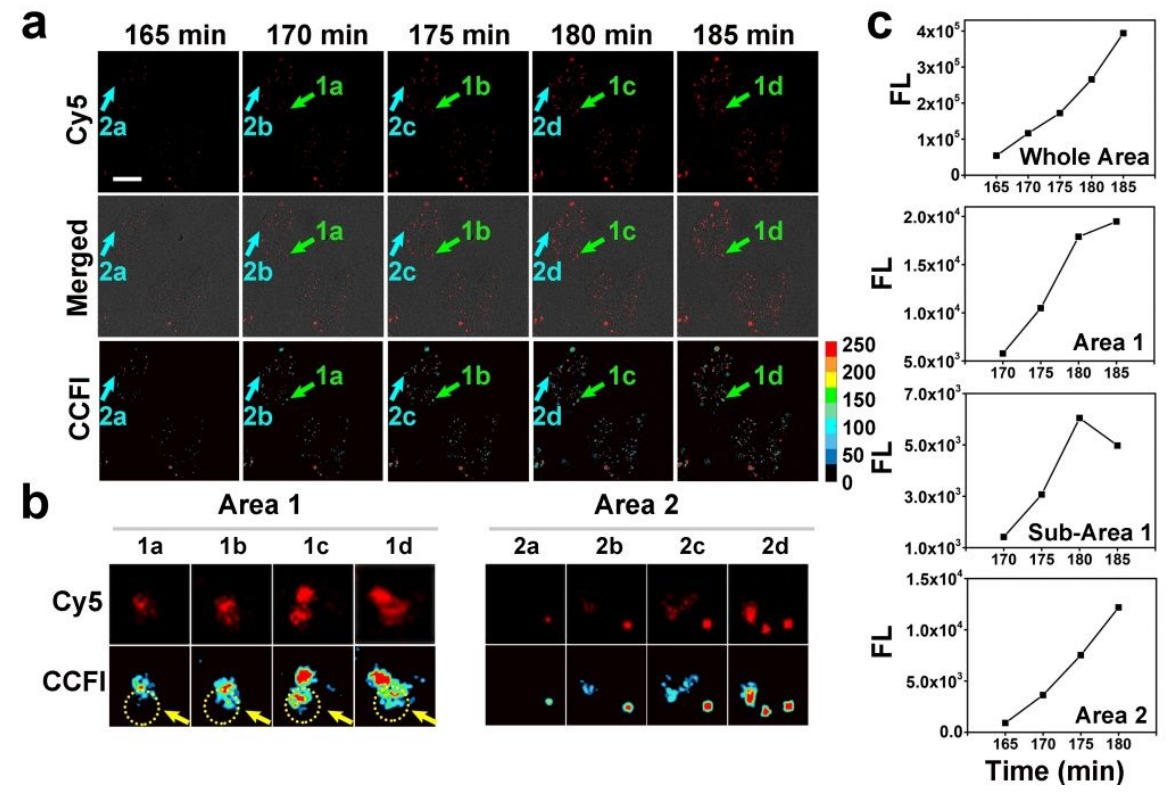

Figure S28. (a) Lifetime study of NEPA products formed within live MCF-7 cells. The red dots represent DNA nanospheres with Cy5-labeled probes. Merged image indicates fluorescence image merged with differential interference contrast (DIC) microscopy-based images. (b) Amplified red dots marked in panel (a) in given areas. Scale for Area 1 and Area 2 is $4.0 \times 4.0 \mu$ m. (c) Incubation time-dependent fluorescence intensity of the whole area of panel (a) and its local areas shown in panel (b). Fluorescence intensity of Cy5 is estimated with Image J software. Scale bar is $25 \mu \mathrm{m}$.

\section{Experimental procedure:}

The real-time fluorescence analysis, including cell culture, transfection with NEPA probes and real-time fluorescence analysis, were performed using the same procedure as Figure S27. However, MCF-7 cells were used instead of HeLa cells. 
Compared with in Figure 3d, Z-stack images of more MCF-7 cells were collected. As shown in Figure S29, one can see that the vast majority of fluorescence peaks of FAM and Cy5 appear at the same location on the different Z-axis planes.

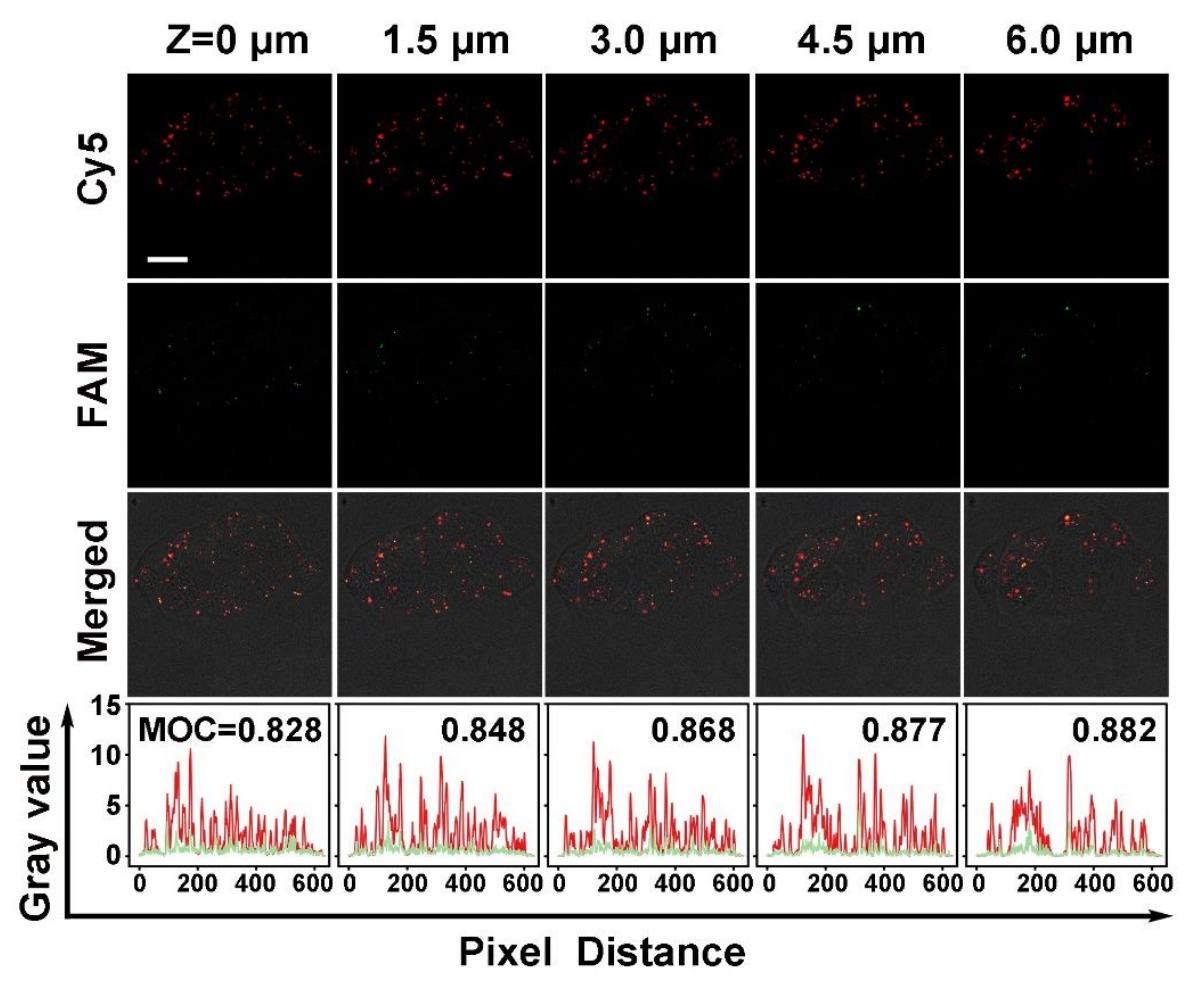

Figure S29. Z-stack images of MCF-7 cells treated by NEPA probes in the wide field of view. (a) Z-stack images of MCF-7 cells treated by NEPA probes. Fluorescence intensity of Cy5 and FAM is estimated with Image J software. Scale bar is $25 \mu \mathrm{m}$. MOC indicates the Manders overlap coefficient quantifying the degree of colocalization of the two fluorescence signals.

\section{Experimental procedure:}

The Z-stack images assay, including cell culture, transfection with NEPA probes and real-time fluorescence analysis, were performed using the same procedure as Figure $3 \mathrm{~d}$. However, the fluorescence imaging was performed in the wider field of view. 


\section{Programmability and versatility of NEPA technique}

Since the original DNA building blocks for the self-assembly of NS superstructures (e.g., HA, HB and HC) are independent of target sequence and the growth of NS superstructures initiated by target species cannot occur without the help of TH probe, NEPA system is able to be extended from the detection of nucleic acids to the sensing of non-nucleic acid targets, for example proteins if lengthening TP probe by adding targeting ligand aptamer. Nucleolin is a nucleolar protein playing a multifunctional role in remodeling of chromatin structure, replication and recombination of rDNA, transcription, maturation and packing of rRNA, assembly of ribosome and nucleocytoplasmic shuttling. ${ }^{16-17}$ Studies have reported that nucleolin is commonly overexpressed on the membrane of many tumor cells compared with the normal counterparts. ${ }^{18}$ The intracellular in situ imaging can reveal the vital information on the subcellular localization and expressed level of nucleolin for the medical profession, ${ }^{19}$ which will promote the understanding of nucleolin function during the initiation and progression of human cancer. Since AS1411 as a nucleolin aptamer displays an excellent cancer cell-targeting property and is suitable for specific cancer cell imaging and targeted drug delivery by binding to the surface nucleolin, ${ }^{20-22}$ As1411 was chosen as the recognizing element to adapt NEPA system for implementing the intracellular fluorescence imaging of nucleolin and for differentiating cancer cells from normal ones. For this purpose, we designed Trigger AS1411 (TA) to contain specific recognition site for nucleoclin and triggering fragment for initiating the NEPA assembly. As shown in Figure S30, TA band (Lane 1) can be distinguished from the hairpin components (Lanes 2, 3 and 4) because of its slightly higher electrophoretic mobility. Only one gel band is observed in Lane 5 owing to the no-interaction between HA, HB and HC. The residual DNA band in Lane 8 should be the TA because its band position is identical to the band in Lane 1 and TA is not consumed during NEPA assembly. The substantial difference in the number and position of gel bands between Lane 5 and Lane 8 demonstrate that TA indeed initiated the NEPA assembly, forming the NS superstructures. The confocal fluorescence images of several living cells are shown in Figure S31, where two cancerous cells and one normal liver cell were explored. As expected, the high red fluorescence signal was detected in MCF-7 cells and the moderate fluorescence signal was observed in HeLa cells, indicating the formation of DNA NS superstructures.22-24 This is because the TA probe can be internalized into nucleolin-overexpressed cells by receptor-mediated endocytosis and its triggering fragment activates the hybridization between three transfected DNA hairpin components (HA, HB and HC-Cy5) to varying degrees, thereby realizing the intracellular imaging of nucleolin membrane protein. However, no obvious fluorescent signal is detected in L-02 control cells. This is because the normal liver cells have no the overexpressed nucleolin ${ }^{25}$ and the cellular internalization of TA as well as the subsequent reactions cannot occur. The experimental results on the expression level of nucleolin in the three cell lines are in good agreement with the literature reports. ${ }^{16,26-30}$ To evaluate the cellular internalization efficacy of TA and to directly compare the imaging capability of NEPA system with non-amplification-based counterpart (Fluorescence in situ binding, FISB) system, TA-Cy5 as the control was used to implement the cellular imaging. As shown in the right panel (FISB) of Figure S31, the fluorescence intensities of confocal images of MCF-7 and HeLa cells were considerably compromised, but the trend of fluorescence intensity change (MCF-7 > HeLa > L-02) is consistent with that of panel NEPA, displaying the dependence of fluorescence signal of NEPA system on the cellular internalization of TA besides the superior sensitivity of NEPA system to FISB counterpart.

A further comparison between the number of NEPA assembly-based DNA NS superstructures and the intracellular distribution of TA-Cy5 by FISB-based internalization was statistically evaluated by flow cytometry that allows one to collect fluorescence data from a large population of cells. As shown in Figure S32, the flow cytometric data measured by NEPA-based strategy and FISB technique are in general agreement with the recorded data from the confocal images of cells (Figure S31), demonstrating the assay sensitivity and reliability of NEPA-based in situ fluorescence imaging. 


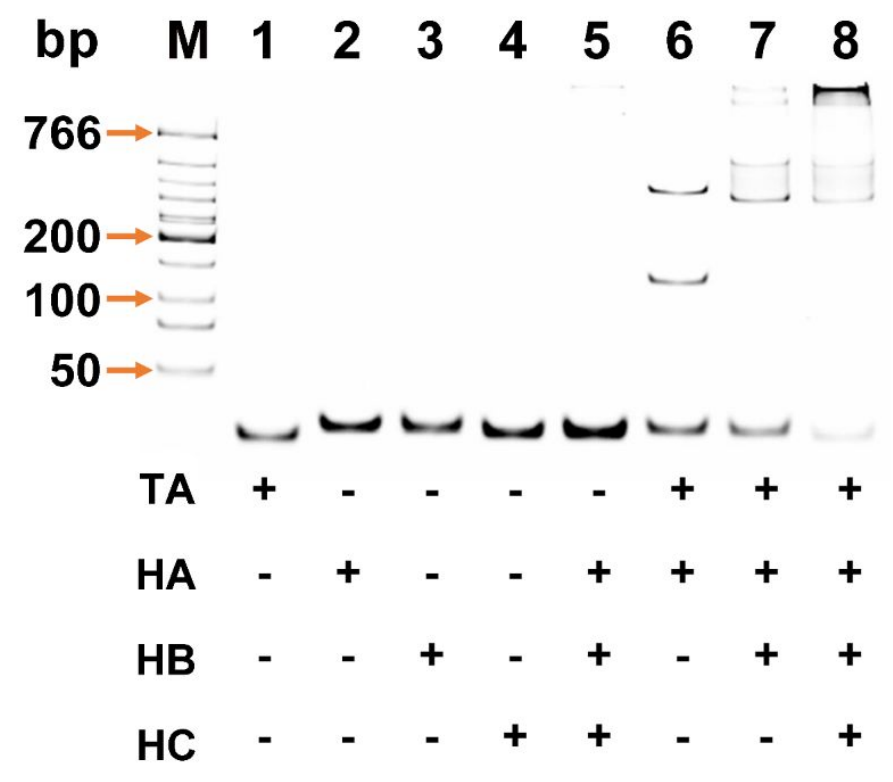

Figure S30. Gel electrophoresis image of NEPA assembly triggered by the Trigger AS1411 (TA) probe.

\section{Experimental procedure:}

The assembly solution was prepared by adding required DNA probes into PBS buffer and the solution volume was adjusted to 25 $\mu \mathrm{L}$. The final concentration of DNA oligonucleotides in the reaction solution were as follows: $800 \mathrm{nM} \mathrm{HA}, 800 \mathrm{nM}$ HB, $800 \mathrm{nM}$ $\mathrm{HC}$ and $200 \mathrm{nM}$ TA (at a molar ratio of 4:4:4:1). After incubating at $37^{\circ} \mathrm{C}$ for 120 min, the resulting solution was stored at $4{ }^{\circ} \mathrm{C}$. The self-assembled products were characterized by 12\% nPAGE analysis. More details are seen in the section of "METHODS". For the other samples, an equal volume of PBS buffer was used instead of the corresponding probes. The symbols, “+” and “--", indicate in the presence and absence of the strands, respectively. Low MW DNA ladder (New England Biolabs, China) was used as the marker. 
a
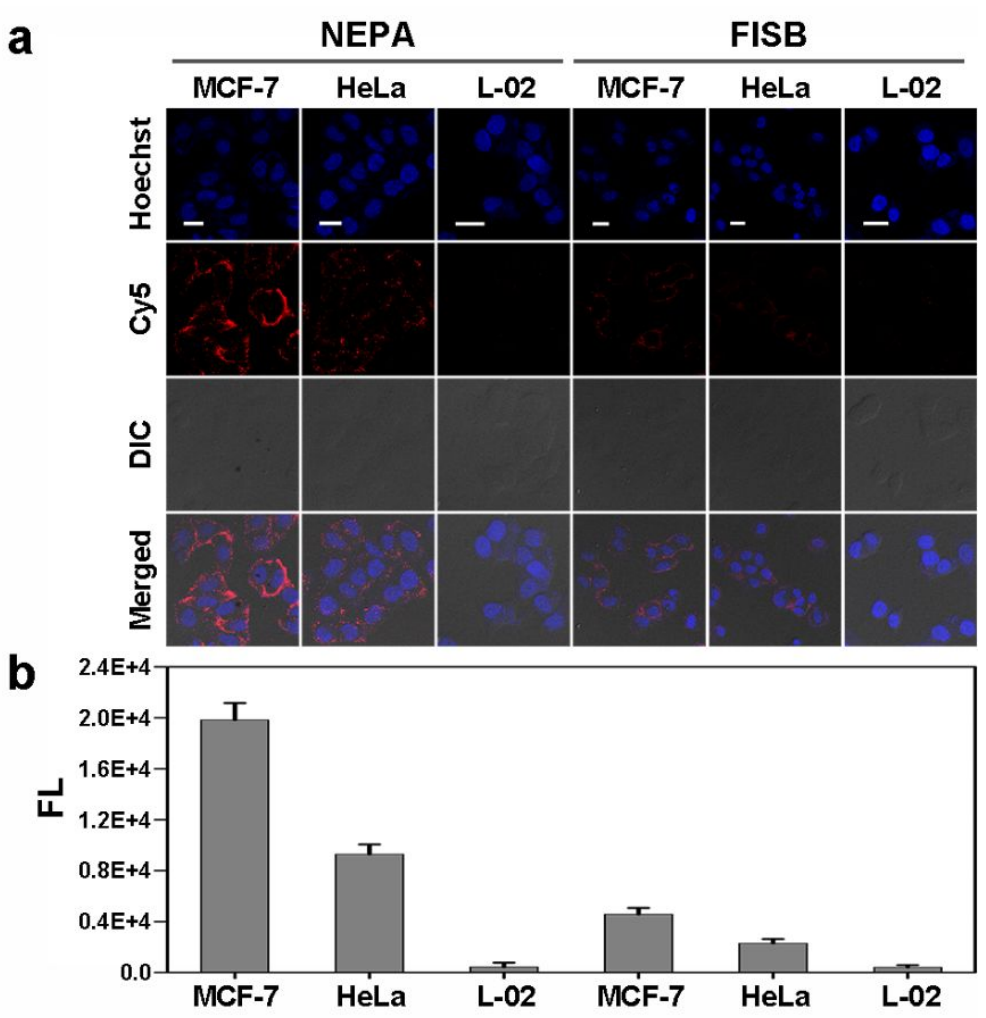

Figure S31. Capability of NEPA-based system to sense the difference in the expression level of nucleolin in different cell lines. (a) NEPA-based confocal imaging of MCF-7 cells, HeLa cells and L-02 cells. The red fluorescence represents DNA NS with Cy5-labeled HC probe. Fluorescence in situ binding (FISB) assay without signal amplification effect serves as control. The scale bar is $25 \mu \mathrm{m}$. (b) The corresponding fluorescence intensity of cell images in (a). Image J software was used to measure the fluorescence intensity of cell images. Error bars represent the standard deviations of three independent measurements.

\section{Experimental procedure:}

NEPA: After grown to 70 80\% confluency and washed with PBS buffer, the cells were incubated in $400 \mu \mathrm{L}$ of PBS buffer-based solution containing $50 \mathrm{nM}$ TA probes at $37^{\circ} \mathrm{C}$ for $1 \mathrm{~h}$. The resulting cells were washed with PBS buffer and incubated at $37^{\circ} \mathrm{C}$ for $220 \mathrm{~min}$ in $400 \mu \mathrm{L}$ of Opti-MEM medium-based solution prepared to contain the mixture of HA, HB, HC-Cy5 (each $2 \mu \mathrm{L}, 10 \mu \mathrm{M}$ ) and Lip3000 according to the instruction. Then, the cells were washed thrice with PBS buffer and fixed in 4\% polyformaldehyde for $15 \mathrm{~min}$. Before confocal imaging, the cell nuclei were stained by incubating in $500 \mu \mathrm{L}$ of $12.5 \mu \mathrm{g} / \mathrm{mL}$ Hoechst 33342 solution for 15 min and washing thrice with PBS buffer. Afterwards, the coverslips were separately treated as follows: the anti-fluorescence quenching sealing agents were added to a rectangular slide, then the coverslip was inverted onto the rectangular slide, and the cells on the coverslip were imaged on a Leica SP8 laser scanning confocal microscope (Leica, Germany).

FISB: After grown to 70 80\% confluency and washed with PBS buffer, the cells were incubated in $400 \mu \mathrm{L}$ of PBS buffer-based solution containing $50 \mathrm{nM}$ TA-Cy5 probes at $37^{\circ} \mathrm{C}$. After $1 \mathrm{~h}$, the cells were washed with PBS buffer and then fixed in $4 \%$ polyformaldehyde for $15 \mathrm{~min}$. Before confocal imaging, all cell nuclei were stained with $500 \mu \mathrm{L}$ of $12.5 \mu \mathrm{g} / \mathrm{mL} \mathrm{Hoechst} 33342$ solution for $15 \mathrm{~min}$ and washed three times with PBS buffer. Afterwards, the coverslips were separately treated as follows: the anti-fluorescence quenching sealing agents were added to a rectangular slide, then the coverslip was inverted onto the rectangular slide, and the cells on the coverslip were imaged on a Leica SP8 laser scanning confocal microscope (Leica, Germany). 

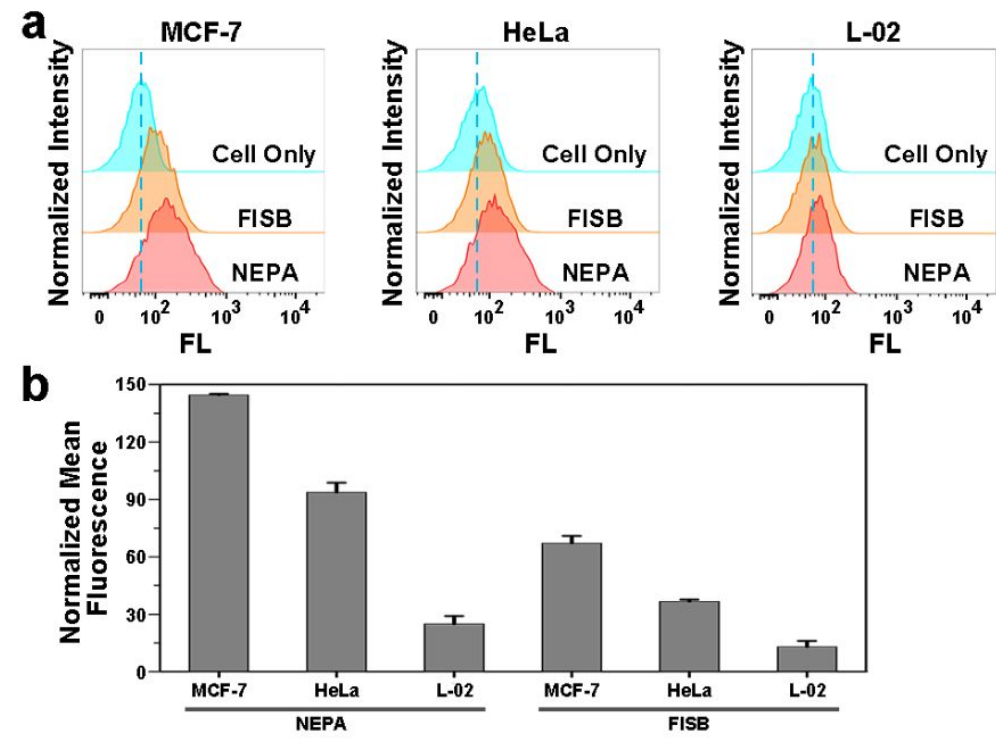

Figure S32. (a) Capability of NEPA-based system to sense the difference in nucleolin expression between MCF-7 cells, HeLa cells and L-02 cells by flow cytometry. (b) Representative histograms of fluorescence signal recorded from (a). FISB assay without signal amplification effect serves as control.

\section{Experimental procedure:}

NEPA: Cells were cultured on the 6-well plastic-bottom plate coverslips for $24 \mathrm{~h}$. After grown to $70 \sim 80 \%$ confluency and washed thrice with PBS buffer, the cells were incubated in $1000 \mu \mathrm{L}$ of PBS buffer-based solution containing $50 \mathrm{nM}$ TA probes at $37^{\circ} \mathrm{C}$ for $1 \mathrm{~h}$. The resulting cells were washed with PBS buffer and incubated at $37^{\circ} \mathrm{C}$ for $220 \mathrm{~min}$ in $1000 \mu \mathrm{L}$ of Opti-MEM medium-based solution prepared to contain the mixture of HA, HB, HC-Cy5 (each $5 \mu \mathrm{L}, 10 \mu \mathrm{M}$ ) and Lip3000 according to the instruction. After kept at $37{ }^{\circ} \mathrm{C}$ for $220 \mathrm{~min}$, the cells were washed thrice with PBS buffer, separated by trypsin digestion and re-suspended in 1000 $\mu \mathrm{L}$ of PBS buffer. Finally, a $633 \mathrm{~nm}$ laser was used as exciting source to analyze the samples by measureing the fluorescence intensity of Cy5.

FISB: Cells were cultured on the 6-well plastic-bottom plate coverslips for $24 \mathrm{~h}$. After grown to $70 \sim 80 \%$ confluency and washed with PBS buffer, the cells were incubated in $1000 \mu \mathrm{L}$ of PBS buffer-based solution containing $50 \mathrm{nM}$ TA-Cy 5 probes at $37^{\circ} \mathrm{C}$. After $1 \mathrm{~h}$, the cells were washed thrice with PBS buffer, separated by trypsin digestion and re-suspended in $1000 \mu \mathrm{L}$ of PBS buffer. Finally, a $633 \mathrm{~nm}$ laser was used as exciting source to analyze the samples by measuring the fluorescence intensity of Cy5. 


\section{References}

1. LaBean, T. H.; Yan, H.; Kopatsch, J.; Liu, F.; Winfree, E.; Reif, J. H.; Seeman, N. C. Construction, Analysis, Ligation, and Self-Assembly of DNA Triple Crossover Complexes. J. Am. Chem. Soc. 2000, 122, 1848-1860.

2. Xue, C.; Zhang, S. X.; Ouyang, C. H.; Chang, D.; Salena, B. J.; Li, Y.; Wu, Z. S. Target-Induced Catalytic Assembly of Y-Shaped DNA and Its Application for In Situ Imaging of MicroRNAs. Angew. Chem., Int. Ed. 2018, 57, 9739-9743.

3. Zheng, J.; Zhu, G.; Li, Y.; Li, C.; You, M.; Chen, T.; Song, E.; Yang, R.; Tan, W. A Spherical Nucleic Acid Platform Based on Self-Assembled DNA Biopolymer for High-Performance Cancer Therapy. ACS Nano 2013, 7, 6545-6554.

4. Zhang, C.; Tian, C.; Li, X.; Qian, H.; Hao, C.; Jiang, W.; Mao, C. Reversibly Switching the Surface Porosity of a DNA Tetrahedron. J. Am. Chem. Soc. 2012, 134, 11998-12001.

5. Yin, P.; Choi, H. M.; Calvert, C. R.; Pierce, N. A. Programming Biomolecular Self-Assembly Pathways. Nature 2008, 451, 318-322.

6. Zhang, D. Y.; Seelig, G. Dynamic DNA Nanotechnology Using Strand-Displacement Reactions. Nat. Chem. 2011, 3, $103-113$.

7. Chen, X. Expanding the Rule Set of DNA Circuitry with Associative Toehold Activation. J. Am. Chem. Soc. 2011, 134, $263-271$.

8. Karunanayake Mudiyanselage, A. P.; Yu, Q.; Leon-Duque, M. A.; Zhao, B.; Wu, R.; You, M. Genetically Encoded Catalytic Hairpin Assembly for Sensitive RNA Imaging in Live Cells. J. Am. Chem. Soc. 2018, 140, 8739-8745.

9. Tyagi, S.; Kramer, F. R. Molecular Beacons: Probes that Fluoresce upon Hybridization. Nat. Biotechnol. 1996, 14, $303-308$.

10. Tyagi, S.; Bratu, D. P.; Kramer, F. R. Multicolor Molecular Beacons for Allele Discrimination. Nat. Biotechnol. 1998, 16, $49-53$.

11. Schmittgen, T. D.; Lee, E. J.; Jiang, J.; Sarkar, A.; Yang, L.; Elton, T. S.; Chen, C. Real-Time PCR Quantification of Precursor and Mature MicroRNA. Methods 2008, 44, 31-38.

12. Graybill, R. M.; Bailey, R. C. Emerging Biosensing Approaches for MicroRNA Analysis. Anal. Chem. 2015, 88, 431-450.

13. Pritchard, C. C.; Cheng, H. H.; Tewari, M. MicroRNA Profiling: Approaches and Considerations. Nat. Rev. Genet. 2012, 13, 358-369.

14. Ying, Z.-M.; Wu, Z.; Tu, B.; Tan, W.; Jiang, J.-H. Genetically Encoded Fluorescent RNA Sensor for Ratiometric Imaging of MicroRNA in Living Tumor Cells. J. Am. Chem. Soc. 2017, 139, 9779-9782.

15. Zhang, Z.; Wang, Y.; Zhang, N.; Zhang, S. Self-Assembly of Nucleic Acid Molecular Aggregates Catalyzed by a Triple-Helix Probe for miRNA Detection and Single Cell Imaging. Chem. Sci. 2016, 7, 4184-4189.

16. Wu, J.; Song, C.; Jiang, C.; Shen, X.; Qiao, Q.; Hu, Y. Nucleolin Targeting AS1411 Modified Protein Nanoparticle for Antitumor Drugs Delivery. Mol. Pharm. 2013, 10, 3555-3563. 
17. Sun, D.; Guo, K.; Shin, Y.-J. Evidence of the Formation of G-Quadruplex Structures in the Promoter Region of the Human Vascular Endothelial Growth Factor Gene. Nucleic Acids Res. 2010, 39, 1256-1265.

18. Wei, W.; He, X.; Ma, N. DNA-Templated Assembly of a Heterobivalent Quantum Dot Nanoprobe for Extra-And Intracellular Dual-Targeting and Imaging of Live Cancer Cells. Angew. Chem., Int. Ed. 2014, 53, 5573-5577.

19. Koo, H.; Park, I.; Lee, Y.; Kim, H. J.; Jung, J. H.; Lee, J. H.; Kim, Y.; Kim, J.-H.; Park, J. W. Visualization and Quantification of MicroRNA in a Single Cell Using Atomic Force Microscopy. J. Am. Chem. Soc. 2016, 138, 11664-11671.

20. Li, S.; Jiang, Q.; Liu, S.; Zhang, Y.; Tian, Y.; Song, C.; Wang, J.; Zou, Y.; Anderson, G. J.; Han, J.-Y. A DNA Nanorobot Functions as a Cancer Therapeutic in Response to a Molecular Trigger In Vivo. Nat. Biotechnol. 2018, 36, 258-264.

21. Qiu, L.; Wu, C.; You, M.; Han, D.; Chen, T.; Zhu, G.; Jiang, J.; Yu, R.; Tan, W. A Targeted, Self-Delivered, and Photocontrolled Molecular Beacon for mRNA Detection in Living Cells. J. Am. Chem. Soc. 2013, 135, 12952-12955.

22. Shen, Y.; Tian, Q.; Sun, Y.; Xu, J.-J.; Ye, D.; Chen, H.-Y. ATP-Activatable Photosensitizer Enables Dual Fluorescence Imaging and Targeted Photodynamic Therapy of Tumor. Anal. Chem. 2017, 89, 13610-13617.

23. Zhang, P.; Cheng, F.; Zhou, R.; Cao, J.; Li, J.; Burda, C.; Min, Q.; Zhu, J. J. DNA-Hybrid-Gated Multifunctional Mesoporous Silica Nanocarriers for Dual-Targeted and MicroRNA-Responsive Controlled Drug Delivery. Angew. Chem., Int. Ed. 2014, 53, $2371-2375$.

24. Yang, X.; Xia, L.; Zhen, L.; Fang, P.; Ren, J.; Qu, X. Near-Infrared Light-Triggered, Targeted Drug Delivery to Cancer Cells by Aptamer Gated Nanovehicles. Adv. Mater. 2012, 24, 2890-2895.

25. Hu, H.; Dai, A.; Sun, J.; Li, X.; Gao, F.; Wu, L.; Fang, Y.; Yang, H.; An, L.; Wu, H. Aptamer-Conjugated Mn $\mathrm{O}_{4} @ \mathrm{SiO}_{2} \mathrm{Core}_{-} \mathrm{Shell}$ Nanoprobes for Targeted Magnetic Resonance Imaging. Nanoscale 2013, 5, 10447-10454.

26. Keefe, A. D.; Supriya, P.; Andrew, E. Aptamers as Therapeutics. Nat. Rev. Drug Discov. 2010, 9, 660-660.

27. Nimjee, S. M.; Rusconi, C. P.; Sullenger, B. A. Aptamers: an Emerging Class of Therapeutics. Annu. Rev. Med. 2005, $56,555-583$.

28. Zhang, J. M.; Chen, R. E.; Fang, X. F.; Chen, F. Q.; Wang, Y. T.; Chen, M. W. Nucleolin Targeting AS1411 Aptamer Modified pH-Sensitive Micelles for Enhanced Delivery and Antitumor Efficacy of Paclitaxel. Nano Res. 2015, 8, 201-218.

29. Liu, J.; Wei, T.; Zhao, J.; Huang, Y.; Deng, H.; Kumar, A.; Wang, C.; Liang, Z.; Ma, X.; Liang, X.-J. Multifunctional Aptamer-Based Nanoparticles for Targeted Drug Delivery to Circumvent Cancer Resistance. Biomaterials 2016, 91, 44-56.

30. Zhou, X.; Li, Y.; Wu, H.; Huang, W.; Ju, H.; Ding, S. A Amperometric Immunosensor for Sensitive Detection of Circulating Tumor Cells Using a Tyramide Signal Amplification-Based Signal Enhancement System. Biosens. Bioelectron. 2019, 130, 88-94. 